\title{
End-product Inhibition of Photosynthesis in Prunus cerasus L. in Response to Whole-plant Source-Sink Manipulation
}

\author{
Desmond R. Layne ${ }^{1}$ and J.A. Flore ${ }^{2}$ \\ Department of Horticulture, Michigan State University, East Lansing, MI 48824-1325

\begin{abstract}
Additional index words. carboxylation efficiency, chlorophyll fluorescence, $\mathrm{CO}_{2}$ compensation point, continuous lighting, dark respiration, defoliation, feedback inhibition, internal $\mathrm{CO}$, concentration, light compensation point, photochemical efficiency, photoinhibition, photorespiration, photosystem II, rubisco, RuBP, senescence, sorbitol, sour cherry, specific leaf density, stomatal conductance, stomatal limitations, starch, sucrose
\end{abstract}

\begin{abstract}
The source-sink ratio of l-year-old, potted 'Montmorency' sour cherry (Prunus cerasus) trees was manipulated by partial defoliation (D) or continuous lighting $(C L)$ to investigate the phenomenon of end-product inhibition of photosynthesis. Within 24 hours of $\mathrm{D}$, net $\mathrm{CO}_{2}$ assimilation rate (A) of the most recently expanded source leaves of $\mathrm{D}$ plants was significantly higher than nondefoliated (control) plants throughout the diurnal photoperiod. Between 2 and 7 days after D, A was $30 \%$ to $50 \%$ higher and stomatal conductance rate $(\mathrm{g}$,) was $50 \%$ to $100 \%$ higher than in controls. Estimated carboxylation efficiency $(k)$ and ribulose-1,5-bisphosphate (RuBP) regeneration rate increased significantly within 2 days and remained consistently higher for up to 9 days after $D$. Leaf starch concentration and dark respiration rate decreased but sorbitol and sucrose concentration increased after $D$. The diurnal decline in $A$ in the afternoon after $D$ may have been due to feedback inhibition from accumulation of soluble carbohydrates (sucrose and sorbitol) in the cytosol. This diurnal decline indicated that trees were sink limited. By 9 days after D, photochemical efficiency was significantly higher than in control plants. In the long term, leaf senescence was delayed as indicated by higher $\mathbf{A}$ and $\mathbf{g}_{s}$ in combination with higher chlorophyll content up to 32 days after $D$. CL resulted in a significant reduction of $A, g_{s}$, $k$, variable chlorophyl fluorescence $\left(F_{v}\right)$, photochemical efficiency, and estimated RuBP regeneration rate of the most recently expanded source leaves within 1 day. During the exposure to $C L$, A was reduced 2- to 3-fold and $k$ was reduced up to 4-fold. The normal linear relationship between $A$ and $\mathrm{g}_{s}$ was uncoupled under $C L$ indicating that $A$ was not primarily limited by $g_{s}$ and since internal $\mathrm{CO}_{2}$ concentration was not significantly affected, the physical limitation to $\mathrm{A}$ imposed by the stomata was negligible. The decrease in $F_{v}$ and photochemical efficiency indicated that leaves were photoinhibited within 1 day. The decrease in instantaneous chlorophyll fluorescence after at least 1 day of CL indicated that there was a reversible regulatory mechanism whereby the damage to photosystem II reaction centers was repaired. Leaf chlorophyll content was not altered by 1,2, or 3 days of exposure to CL, indicating that photooxidation of chlorophytl did not occur. The time to full photosynthetic recovery from CL increased as the duration of exposure increased. CL plants that were photoinhibited accumulated significant starch in the chloroplast in a companion study (Layne and Flore, 1993) and it is possible that an orthophosphate limitation in the chloroplast stroma was occurring. D plants that were continuously illuminated were not photosynthetically inhibited. After 7 days of CL, plants that were then partially defoliated yet remained in CL photosynthetically recovered within 5 days to pre-CL values. Under the conditions of this investigation, end-product inhibition of A occurred in young, potted sour cherry trees but the mechanism of action in D plants was different than in CL plants.
\end{abstract}

Plant growth and productivity may be limited by the production or use of photosynthetic carbon compounds (photoassimilates). Sucrose and starch are the primary end-products of leaf photosynthesis inmost higher plants, where sucrose is the main translocated carbohydrate and starch is a temporary storage carbohydrate that accumulates in the chloroplast. Sorbitol, a sugar alcohol, is an additional important translocated form of photoassimilate in Prunus species (Loescher, 1987). The capacity of sink tissues to use

Received for publication 10 Oct. 1994. Accepted for publication 7 Feb. 1995. We gratefully acknowledge the assistance of M.G. Kwantes and J.D. Everard in developing the leaf carbohydrate and chlorophyll analyses. We also thank R.E. Dickson, R. Gee, A.N. Lakso, J. Preiss, and M.N. Sivak for valuable discussions regarding experimentation. F. Kappel, S. Myers, and T. Roper provided critical evaluation and suggestions to improve the manuscript. This research was supported by the Michigan Agricultural Experiment Station and by U.S. Dept. of Agriculture grant no. 88-34132-3380. The cost of publishing this paper was defrayed in part by the payment of page charges. Under postal regulations, this paper therefore must be hereby marked advertisement solely to indicate this fact.

${ }^{1}$ Former graduate research assistant. Currently principal investigator of Horticulture, 129 Atwood Research Facility, Kentucky State Univ., Frankfort, KY 40601, and adjunct assistant professor, Dept. of Horticulture and Landscape Architechture, Univ. of Kentucky, Lexington, KY 40546. To whom reprint requests should be addressed.

${ }^{2}$ Professor photoassimilate is referred to as sink demand or strength, which is the product of sink size and sink activity (Warren Wilson, 1972). Under sink-limiting conditions (Baysdorfer and Bassham, 1985), when source activity exceeds sink demand, photoassimilates may accumulate in the source leaf. Feedback inhibition of sucrose synthesis by sucrose accumulation may account for an inhibition in net $\mathrm{CO}_{2}$ assimilation rate (A) (Herold, 1980). In addition to sucrose accumulation in the cytosol, starch accumulation in the chloroplast has also been correlated with an inhibition of A (Gucci et al., 1991a, 1991b; Schaffer et al., 1986).

Whole-plant manipulation to alter the source-sink ratio has been used for investigating the mechanisms involved in endproduct inhibition of photosynthesis. Whole-plant partial defoliation (D) and continuous lighting (CL) are manipulation techniques that decrease and increase the source-sink ratio, respectively. Although actual sink demand remains unchanged after either treatment, the relative source activity is altered considerably. After $\mathrm{D}$, there are fewer source leaves available to supply the necessary photoassimilate to the sinks so the relative demand per unit available leaf area increases. Often, as a result of D, photosynthetic enhancement of the remaining leaves occurs (Aoki, 1981; Baysdorfer and Bassham, 1985; Layne and Flore, 1992, 1993; Satoh et al., 1977; Tschaplinski and Blake, 1989a; Von Caemmerer 
and Farquhar, 1984; Wareing et al., 1968; Williams and Farrar, 1988). One would not expect end-product inhibition to occur in partially defoliated plants until a sink limited condition occurred. On the other hand, under CL conditions, the same number of source leaves remain but the duration over which photosynthesis can occur is greatly extended, Eventually, source supply will exceed sink demand and photoassimilates will accumulate leading to an end-product inhibition of A (Sawada et al., 1989). Much of the end-product inhibition research conducted has focussed on agronomic and herbaceous plants and, as yet, the definitive mechanisms involved remain to be fully elucidated. This study was conducted to investigate the underlying mechanisms involved in end-product inhibition of a woody plant, namely $P$. cerasus. For a recent review on photoassimilate distribution in Prunus, see Flore and Layne (1995).

In an earlier report (Layne and Flore, 1993), we documented some of the responses of young, potted sour cherry trees to D and
CL. In this paper, we report on five experiments that were conducted to determine how the biochemical and photochemical aspects of photosynthesis were affected in response to D and CL as it relates to end-product inhibition. Since diurnal fluctuations in gas exchange occur in many plant species, we conducted the first experiment to determine whether source-sink manipulation effects were stable throughout die day. We also wanted to determine if A was primarily limited by stomatal conductance rate $\left(g_{s}\right)$ and whether the effect of CL could be reversed by D. In the second experiment, we investigated the early and long-term responses to D. We monitored diurnal gas exchange to determine if trees grown under constant light intensity in a growth chamber would demonstrate a diurnal rhythm of $\mathrm{A}$ and how $\mathrm{D}$ might affect that rhythm. Also, we wanted to determine what specific factors limit $\mathrm{A}$ in the short- and long-term and how D might bring about a photosynthetic rejuvenation in existing leaves. From Expt. 2 it was noted that dark respiration rate $\left(R_{d}\right)$ decreased after $D$. The third experi-

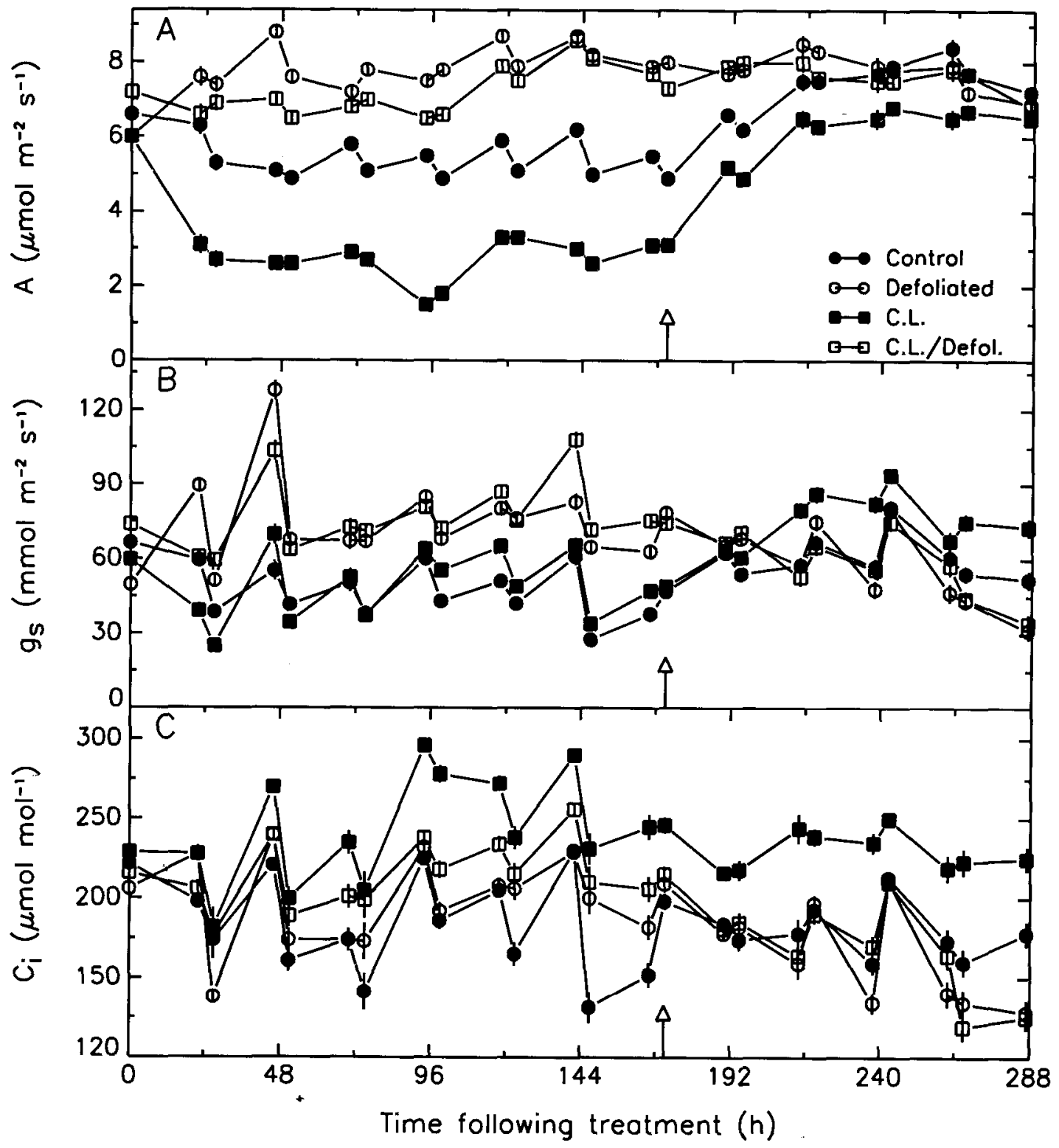

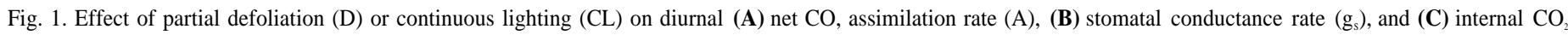
concentration $\left(\mathrm{C}_{\mathrm{i}}\right)$ over time for 1 -year-old, potted sour cherry trees. Treatments: control $=14$-h photoperiod, nondefoliated $(\boldsymbol{O})$; $\mathrm{D}=14$-h photoperiod $(\mathrm{O})$; $\mathrm{CL}=$

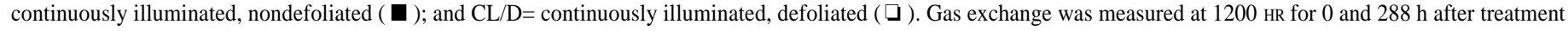

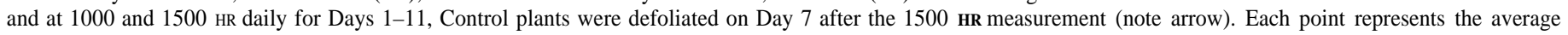
$( \pm \mathrm{SE})$ of 16 leaves. 
ment was conducted to determine how $\mathrm{D}$ affected $\mathrm{R}_{\mathrm{d}}$ and whether leaves became substrate-limited for respiration during the night. In addition, leaf carbohydrates were monitored to determine how carbohydrate partitioning changed after D. The fourth experiment was conducted to determine the effect of CL on diurnal gas exchange and several specific parameters in the short term. The effect of CL on photochemical events and the time to full photosynthetic recovery after CL were examined in experiment five to determine if photosynthetic machinery was damaged by CL. Findings from these experiments have been used to broaden our understanding of end-product inhibition of A in Prunus cerasus.

\section{Materials and Methods}

Experiment 1: Diurnal gas exchange responses to source manipulation

Forty dormant 1-year-old sour cherry trees (P. cerasus 'Montmorency' on $P$. mahaleb rootstock) were planted in 11-liter plastic pots with 9.5 liters of sterilized greenhouse soil mix [5 sandy loam
:3 sphagnum peat: 2 torpedo sand (by volume), $\mathrm{pH}=7.0 \mathrm{]}$. All trees were cut to an active bud ( $0-10 \mathrm{~cm}$ above the bud union) and placed in an environmentally controlled greenhouse (day and night average temperatures were 28 and 23C, respectively). During tree growth, lateral shoots were removed as they developed to ensure plant uniformity in terms of sink strength and plant size. Trees were watered to runoff every 3 days and Peter's soluble $20 \mathrm{~N}-20 \mathrm{P}-20 \mathrm{~K}$ fertilizer (500 ppm) was applied every 3 weeks. Pesticides [5-Odemethylavermectin (abamectin, Avid), cyano(4-fluoro-3phenoxyphenyl)methyl-3(2,2-dichlorethenyl)-2,2-dimethylcyclopropanecarboxylate (cyfluthrin, Decathlon), and d-(2-chlorophenyl)d-(4-chlorophenyl)-5-pyrimidine-methanol (fenarimol, Rubigan) were applied as necessary according to label rates.

After 9 weeks of active growth in the greenhouse, leaf number and total leaf area were determined for each plant. Each plant had about 20-25 fully expanded leaves at this time and new leaves were still emerging. Gas exchange was measured on the four mostrecently fully expanded, source leaves per plant using a portable photosynthesis system (model LCA2; Analytical Development

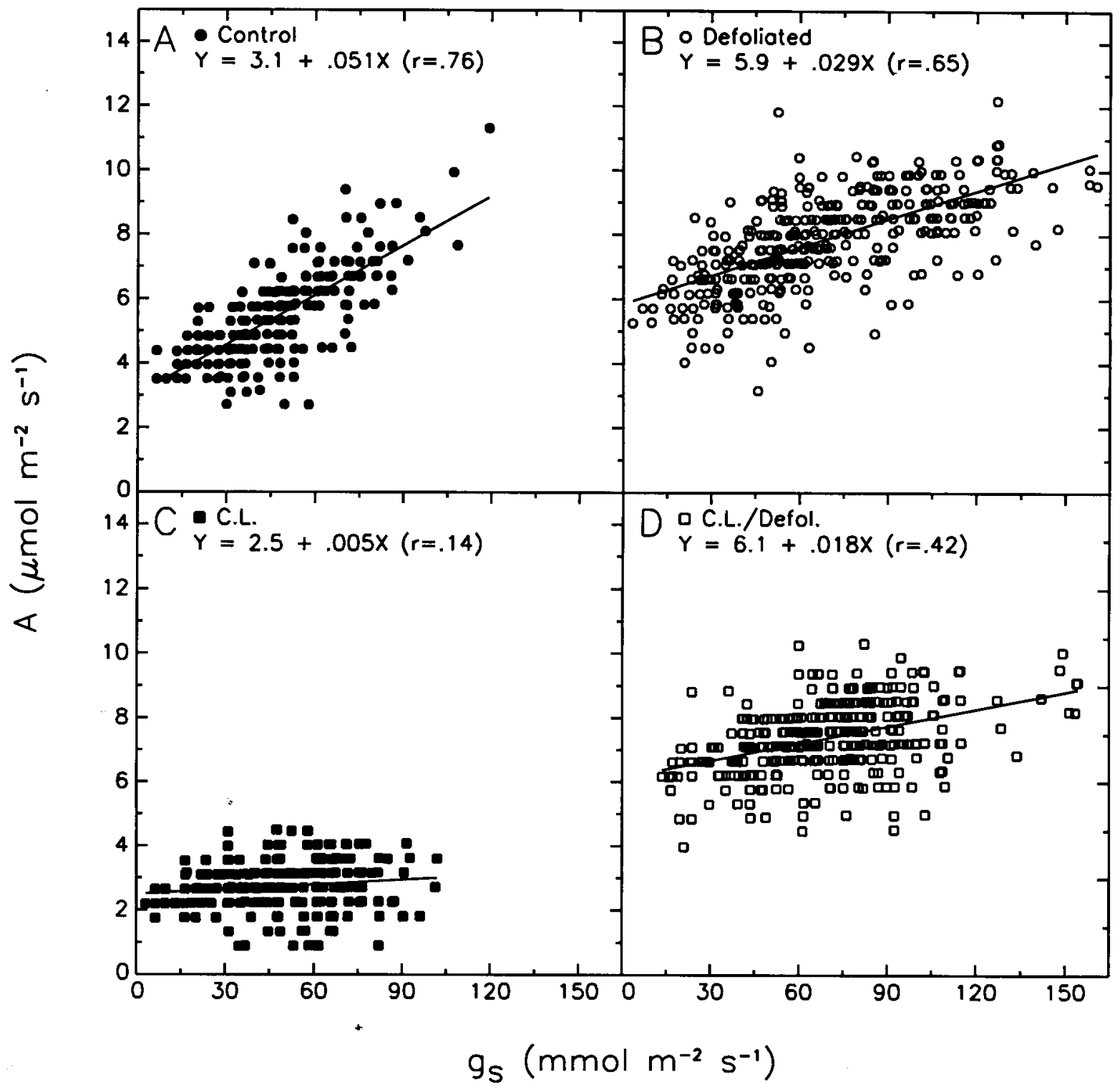

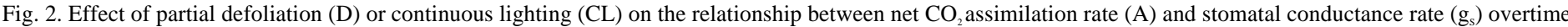

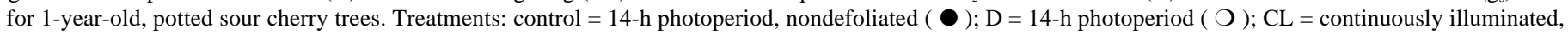

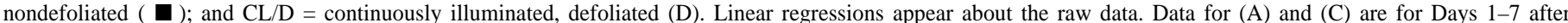
treatment. Data for (B) and (D) are for Days 1-1 2 after treatment. 
Co., Hoddesdon, U. K.) under the following conditions: flow rate $=400 \mathrm{ml} \cdot \mathrm{min}^{-1}$, leaf temperature $=30 \pm 2 \mathrm{C}$, vapor pressure deficit $(\mathrm{VPD})=3 \mathrm{kpa}$, ambient $\mathrm{CO}_{2}=350 \pm 10 \mu \mathrm{l} \cdot \mathrm{liter}^{-1}$, and photosynthetically active radiation $(\mathrm{PAR})>1000 \mu \mathrm{mol} \cdot \mathrm{m}^{-2} \cdot \mathrm{s}^{-1}$ ). The 16 most uniform plants were selected based on total leaf area and initial gas-exchange characteristics and then were moved from the greenhouse to a walk-in plant growth chamber (model PGV36; Conviron Systems of America, Pembina, N.D.). The growth chamber was programmed to the following settings: $0700 \mathrm{HR}$, air temperature $=28 \mathrm{C}$, relative humidity $(\mathrm{RH})=50 \%, \mathrm{PAR}=800$ $\mu \mathrm{mol} \cdot \mathrm{m}^{-2} \cdot \mathrm{s}^{-1} ; 2100 \mathrm{HR}$, air temperature $=23 \mathrm{C}, \mathrm{RH}=50 \%, \mathrm{PAR}=$ $\left.800 \mu \mathrm{mol} \cdot \mathrm{m}^{-2} \cdot \mathrm{s}^{-1}\right)$.

Plants were randomly assigned to one of each of the following treatments: 1) control= nondefoliated, 14-h photoperiod; 2) $\mathrm{D}=$ partially defoliated, 14-h photoperiod; 3) $\mathrm{CL}=24 \mathrm{~h}$ photoperiod, nondefoliated; and 4) $\mathrm{CL} / \mathrm{D}=24 \mathrm{~h}$ photoperiod, D. For the $\mathrm{D}$ treatment, about $70 \%-75 \%$ of the total leaf area was removed by excising all expanded leaves below the fourth fully expanded leaf from the shoot apex. Plants that received a 14-h photoperiod were moved to the other side of the growth chamber behind a light screen (which reduced PAR to $<2 \mu \mathrm{mol} \cdot \mathrm{m}^{-2} \cdot \mathrm{s}^{-1}$; the light compensation point was $14 \mu \mathrm{mol} \cdot \mathrm{m}^{-2} \cdot \mathrm{s}^{-1}$ ) at $2100 \mathrm{HR}$ and then they were returned to the illuminated side at $0700 \mathrm{HR}$ each day. Immediately after the last measurement 7 days after treatment, the control and CL plants were partially defoliated as described above.

Statistical design. Plants were arranged in a completely random- ized design. There were four replicate plants per treatment and the four most recently fully expanded leaves were measured per plant (16 measurements per treatment). Analysis of variance was conducted for treatment comparisons at each date. Linear regression analysis was used to determine the relationship between $\mathrm{A}$ and $\mathrm{g}_{\mathrm{s}}$. The PC version of SAS (Cary, N.C.) was used for statistical analysis.

Gas-exchange measurements. Leaf area was determined according to Kappes $(1985)$, where LA $=($ length $\times$ width $\times 0.671)$. Gas exchange was measured in the growth chamber with the portable photosynthesis system daily on each of the four leaves per plant under the following conditions (flow rate $=400 \mathrm{ml} \cdot \mathrm{min}^{-1}$, leaf temperature $=32 \pm 2 \mathrm{C}, \mathrm{VPD}=4 \mathrm{kpa}$, ambient $\mathrm{CO}_{2}=350 \pm 10$ $\mu \mathrm{l} \cdot$ liter $^{-1}$, and PAR $=800 \mu \mathrm{mol} \cdot \mathrm{m}^{-2} \cdot \mathrm{s}^{-1}$ ). On Days 0 and 12 after treatment, gas exchange was measured beginning at $1200 \mathrm{HR}$. On Days 1-1 1, gas exchange was measured beginning at $1000 \mathrm{HR}$ and then again beginning at $1500 \mathrm{HR}$ for each of the four leaves per plant. Gas-exchange parameters in all experiments were calculated using the computer program of Moon and Flore (1986).

\section{Experiment 2: Short- and long-term effects of D}

As described above, a similar group of dormant 1-year-old sour cherry trees were grown for 9 weeks in the greenhouse, and leaf number, total leaf area, and initial gas-exchange characteristics were determined for each plant. The 16 most uniform plants were selected based on total leaf area and initial gas-exchange characteristics. Selected plants were then moved from the greenhouse to
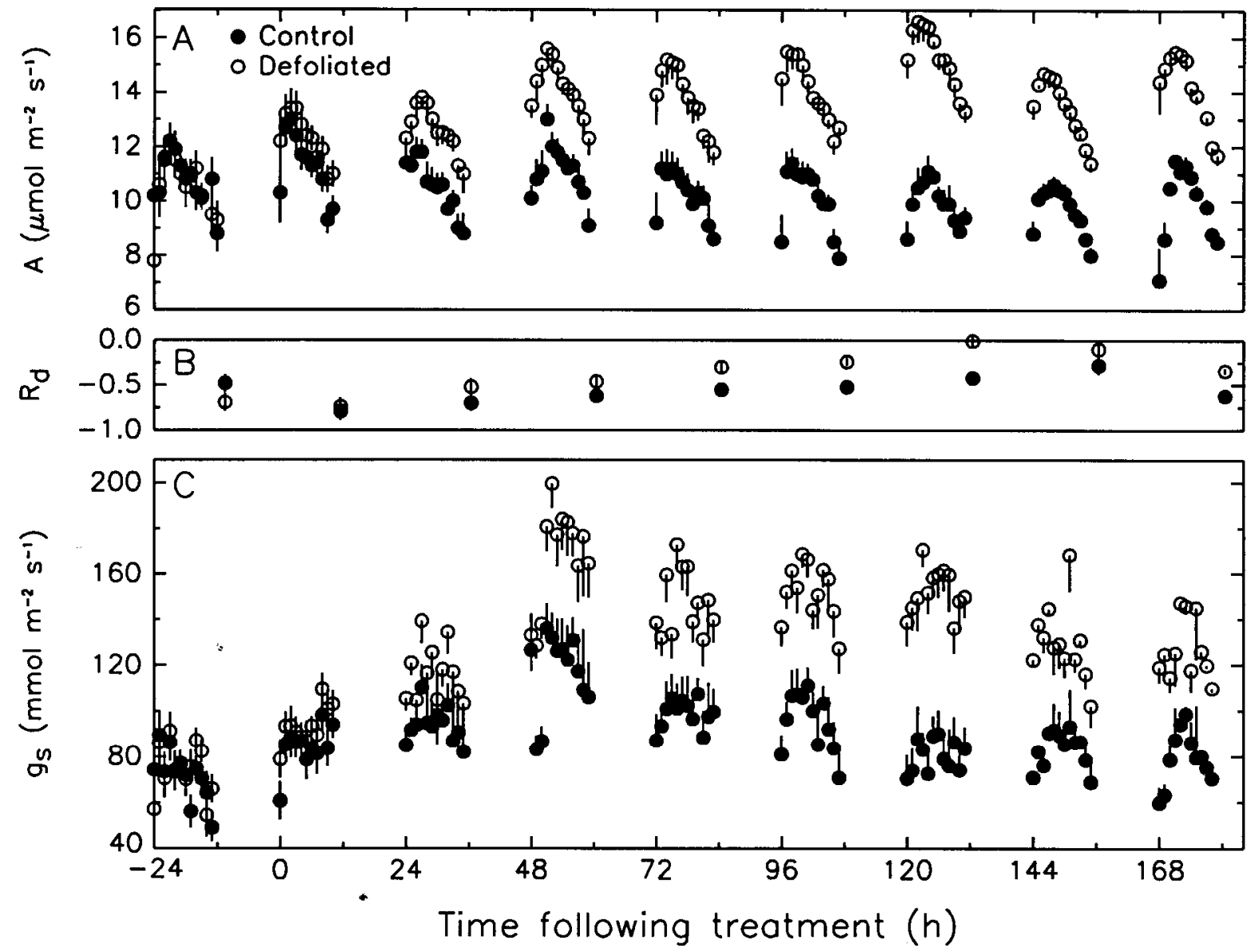

Fig. 3. Time course for the diurnal response of $(\mathbf{A})$ net $\mathrm{CO}_{2}$ assimilation rate $(\mathrm{A}),(\mathbf{B})$ dark respiration rate $\left(\mathrm{R}_{\mathrm{t}}\right.$, expressed as negative $\mathrm{CO}_{2}$ assimilation, same units as for $\mathrm{A})$, and $(\mathbf{C})$ stomatal conductance rate $\left(\mathrm{g}_{\mathrm{s}}\right)$ to partial defoliation in l-year-old, potted sour cherry trees. Treatments: control $=$ non defoliated $(\mathbf{O})$ and defoliated $=$ partially defoliated plant $(\mathrm{O})$. A and $\mathrm{g}_{\mathrm{s}}$ were measured hourly from 0800 to $2000 \mathrm{HR}$ and $\mathrm{R}_{\mathrm{d}}$ was measured at $2130 \mathrm{HR}$ daily. Each point represents the average $(+,-$, or $\pm \mathrm{SE})$ of six leaf measurements. 
the walk-in plant growth chamber that was programmed as above, except that, at $2100 \mathrm{HR}, \mathrm{PAR}=0 \mu \mathrm{mol} \cdot \mathrm{m}^{-2} \cdot \mathrm{s}^{-1}$. D was accomplished as described above.

Gas-exchange measurements. Whole-leaf gas exchange was measured using the open gas-exchange system described by Sams and Flore (1982) and modified as follows: a) art infrared gas analyzer (model 225 MK3; Analytical Development Co.) was used to measure differential $\mathrm{CO}_{2}$ concentrations at the inlet and outlet of the leaf chambers and b) air flow entering the chambers was regulated using the following Matheson Instruments (Horsham, Pa.): 8100 series flowmeters and 8200 series mass flow controllers connected to a model 8219 multichannel Dyna-Blender. Ambient $\mathrm{CO}_{2}$ concentration was measured using a portable infrared gas analyzer and $\mathrm{O}_{2}$ concentration was determined with an oxygen analyzer (model 0-260; Beckman Instruments, Irvine, Calif.). Trees to be measured were moved to an identical walk-in plant growth chamber (set to the same conditions as described above), which was equipped with the assimilation chambers. Unless otherwise indicated, gas-exchange measurements were conducted under the following room conditions: air temperature of $28 \mathrm{C}, 50 \%$ $\mathrm{RH}, \mathrm{PAR}=1000 \mu \mathrm{mol} \cdot \mathrm{m}^{-2} \cdot \mathrm{s}^{-1}$. Four whole-leaf chambers were used simultaneously in which the following conditions were maintained, unless otherwise indicated: inlet $\mathrm{CO}_{2}$ and $\mathrm{O}_{2}, 350 \pm 15$ $\mu \mathrm{l} \cdot \mathrm{liter}^{-1}$ and $21 \mathrm{kpa}$, respectively; leaf temp. $29 \pm 1 \mathrm{C}$; VPD $1.0 \pm$ $0.2 \mathrm{kpa}$; inlet flow rate 3 liters $\cdot \mathrm{min}^{-1}$.

Diurnal gas exchange. On three separate dates (three replicates over time) four plants were selected and two treatments were imposed on two plants each: 1) nondefoliated (control) and 2) D. The fourth fully expanded leaf of each plant was inserted into an individual leaf chamber (where it remained for the duration of the experiment). The day before D was designated as Day O. On Day 1 , the plants were partially defoliated at $0800 \mathrm{HR}$. Gas exchange was measured hourly during the photoperiod from 0800 to $2000 \mathrm{HR}$ and then $\mathrm{R}_{\mathrm{d}}$ was measured at $2130 \mathrm{HR}$ after a 30 min exposure to darkness on Days 0-8. On Day 9, a response to photosynthetic photon flux density (PPFD) was measured (as described below). Plants were then returned to the first walk-in growth chamber that was described above. The three replicates of this experiment were analyzed first by analysis of variance to determine if there was an effect of time on the responses measured. Since there was no significant difference in the responses of plants from the three replicates over time, the data from the replicates were pooled for subsequent statistical analyses.

Long-term effects. After the measurements of diurnal gas exchange and response to PPFD for the three replicates were completed, gas exchange was measured on the same four leaves of all twelve plants with the portable photosynthesis system. Since the experiment was replicated three times over time, the plants from each replicate had three different recovery durations. Leaf areas were measured for all leaves. For each plant, leaves 1-4 were sampled for chlorophyll (as described below) and then leaves were dried in an oven at 80C for 7 days so that specific leaf density (SLD) could be determined (dry weight/unit area).

Chlorophyll determination. Four discs $\left(0.324 \mathrm{~cm}^{2}\right.$ each) were punched from the middle of the lamina (two on either side of the midrib) of each leaf using a paper holepunch. Fresh weight of discs was recorded and then chlorophyll was extracted in $8 \mathrm{ml} \mathrm{n,n-}$ dimethylformamide in darkness at $5 \mathrm{C}$ for $36 \mathrm{~h}$. Absorbance of extracts was read at 664,647 , and $625 \mathrm{~nm}$ on a UV/Vis spectrophotometer (model U-3110; Hitachi, Tokyo). Calculations for chlorophyll $a$, chlorophyll $b$, and protochlorophyll (P) were made according to Moran (1982).

Response to $\mathrm{CO}_{2}$ and low $\mathrm{O}_{2}$. From the same population of 16 plants, the 4 remaining plants were brought to the growth chamber in the laboratory. Gas exchange was measured on Days 0-6 and Day 9 after $\mathrm{D}$, as described above. Carbon dioxide and low $\mathrm{O}_{2}$ response were measured daily between 0930 and $1430 \mathrm{HR}$ (as described below). All four plants were defoliated immediately after the last gas-exchange measurement on Day O.

Gas-exchange measurements for changing environmental con-

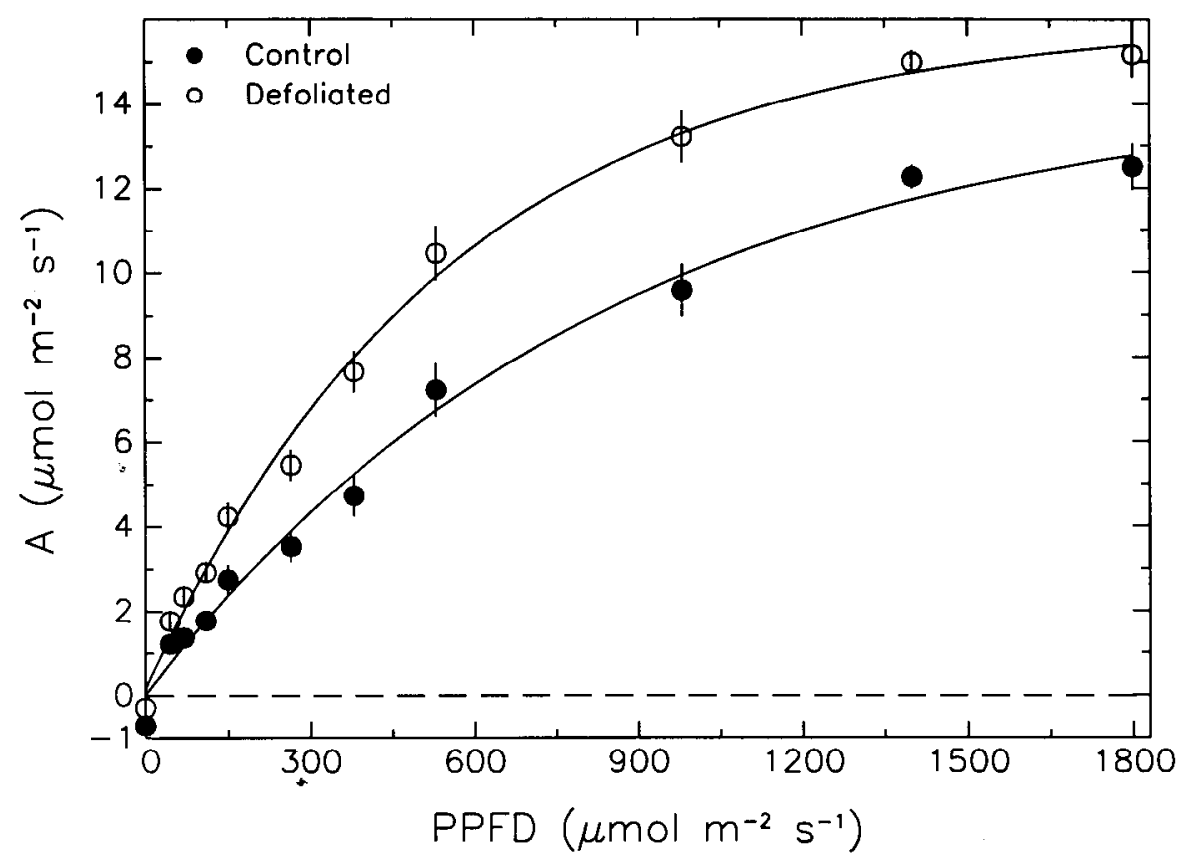

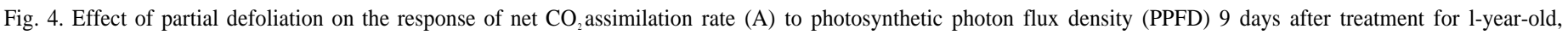

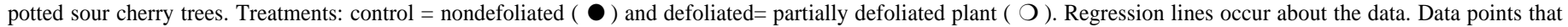
represent the average $( \pm S E)$ of eight leaf measurements appear about the regressions. 
ditions. Response to PPFD was determined by decreasing PPFD in a stepwise manner (15-min acclimation at each step allowed significant time for stomata to adjust) to the following levels 1800 , $1400,980,530,380,265,150,110,70,45$, and $0 \mu \mathrm{mol} \cdot \mathrm{m}^{-2} \cdot \mathrm{s}^{-1}$. Leaf temperature was maintained constant at all PPFD levels. Supplement light to obtain higher PPFDs in the" growth chamber was provided by $400-\mathrm{W}$ metal halide lamps. PPFD levels were produced using a combination of neutral density filters. PAR was measured with a recently calibrated PAR sensor (LI-190; LICOR, Lincoln, Neb.).

Photorespiration rate $\left(\mathrm{R}_{1}\right)$ was estimated by comparing $\mathrm{A}$ at ambient $\mathrm{O}_{2}(21 \mathrm{kPa})$ with that at reduced $\mathrm{O}_{2}(1.5 \mathrm{kPa})$. Response to $\mathrm{CO}_{2}$ was determined by increasing the $\mathrm{CO}_{2}$ concentration stepwise to the following levels: 70, 100, 150, 200, 250, 300, 350, 400, 500, 700, and $900 \mu \mathrm{l} \cdot$ liter $^{-1}$. Leaves were allowed to acclimate for $20 \mathrm{~min}$ at each $\mathrm{CO}_{2}$ level, which allowed sufficient time for stomata to adjust.

Responses of $\mathrm{A}$ to PPFD and $\mathrm{A}$ to internal $\mathrm{CO}_{2}$ concentration $\left(C_{i}\right)$ were analyzed for each treatment by nonlinear regression. Curve fitting was performed using the Marquardt compromise method of successive approximations. The best of it curve, evaluated by analysis of residuals and $r^{2}$, was the monomolecular asymptotic function (Hunt, 1980) of the type

$$
\mathrm{Y}=B\left(1 *\left[1.0-\mathrm{B}(2) e^{-B(3) * X}\right]\right.
$$

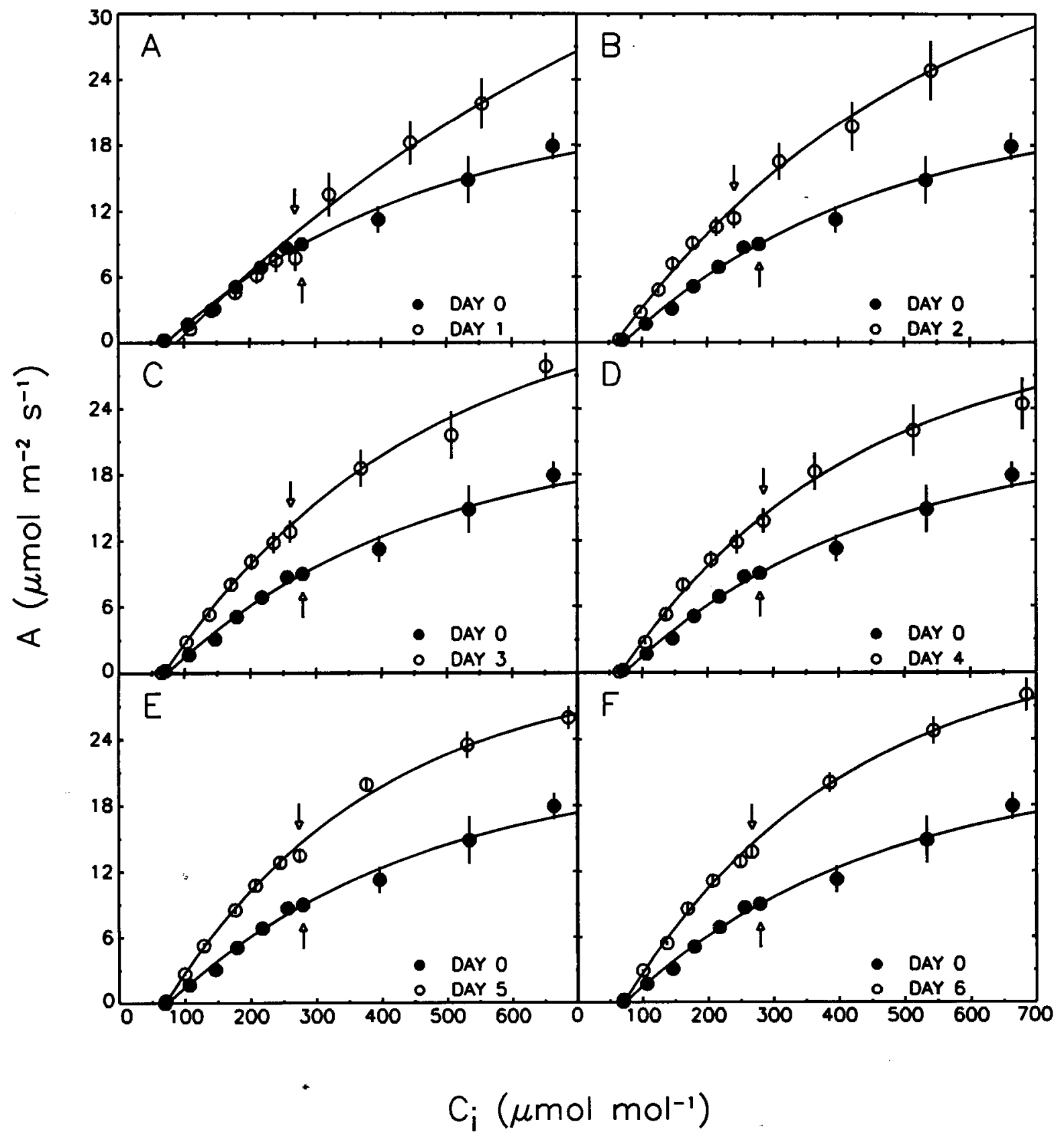

Fig. 5. Effect of partial defoliation (D) on the response over time of net $\mathrm{CO}_{2}$ assimilation rate (A) to internal $\mathrm{CO}_{2}$ concentration $\left(\mathrm{C}_{\mathrm{i}}\right)$ of l-year-old, potted sour cherry trees. Each section (A-F) compares the Day 0 pretreatment response $(\boldsymbol{\square})$ with the treatment response for the subsequent day $(\mathrm{O})$. Treatments: Day $\mathrm{O}=$ before $\mathrm{D}$; Days $1(\mathbf{A})$, 2 (B), 3 (C), 4 (D), 5 (E), and 6 (F) correspond to 1, 2, 3, 4, 5, and 6 days after D, respectively. Regression lines occur about the data. Arrows point to the data collected at ambient $\mathrm{CO}_{2}$ partial pressure $\left(350 \pm 25 \mu \mathrm{l} \cdot \mathrm{liter}^{-1}\right)$. Data points that represent the average ( $\left.\pm \mathrm{SE}\right)$ of four leaf measurements appear about the regressions. 
where $\mathrm{B}(1), \mathrm{B}(2)$, and $\mathrm{B}(3)$ are the asymptotic value, minimum value and rate constant, respectively. This polynomial was selected because it provided direct estimates of specific physiological processes and it exhibited curvilinear features that represented the data. Individual leaf $A$ vs. PPFD and $A$ vs. $C_{i}\left(A_{i}\right)$ response curves were developed using this polynomial.

For the A vs. PPFD curve, dark respiration rate $\left(\mathrm{R}_{\mathrm{d}}\right)$ was calculated at $0 \mu \mathrm{mol} \cdot \mathrm{m}^{-2} \cdot \mathrm{s}^{-1} \mathrm{PPFD}$. Light compensation point (cp) was extrapolated from the curve as the PPFD level at which A was $0 \mu \mathrm{mol} \cdot \mathrm{m}^{-2} \cdot \mathrm{s}^{-1}$. Photochemical efficiency $(\phi)$ was calculated as the slope of the A vs. PPFD curve in the linear portion between 0 and $150 \mu \mathrm{mol} \cdot \mathrm{m}^{-2} \cdot \mathrm{s}^{-1} \mathrm{PPFD}$. From the $\mathrm{AC}_{\mathrm{i}}$ response curve, $\mathrm{CO}_{2} \mathrm{com}-$ pensation point $(\Gamma)$ was extrapolated as the $C_{i}$ at which $A$ was 0 $\mu \mathrm{mol} \cdot \mathrm{m}^{-2} \cdot \mathrm{s}^{-1}$. Estimated carboxylation efficiency $(\mathrm{k})$ was calculated as the slope in the linear portion of the $\mathrm{AC}_{\mathrm{i}}$ curve. Stomatal limitation to $\mathrm{A}\left(\mathrm{l}_{\mathrm{g}}\right)$ was calculated according to the differential method of Jones (1985). Maximum net $\mathrm{CO}_{2}$ assimilation rate $\left(\mathrm{A}_{\max }\right)$ was determined as the A at $900 \mu \mathrm{l} \cdot \operatorname{liter}^{-1} \mathrm{CO}_{2}$. Ribulose-1,5bisphosphate $(\mathrm{RuBP})$ regeneration rate limitations were expressed by a reduced $\mathrm{A}$ at saturating $\mathrm{CO}_{2}$ concentrations (Farquhar and Sharkey, 1982). Linear regression analysis was used to determine photochemical and carboxylation efficiencies from the A vs. PPFD and $\mathrm{AC}_{\mathrm{i}}$ curves, respectively. Homogeneity of the independent regressions was evaluated by Student's $t$ test (Steele and Torie, 1980).

Experiment 3: $D$ effects on $R_{\mathrm{d}}$ and leaf carbohydrate content

As described above, a similar group of dormant 1-year-old sour cherry trees was grown for 9 weeks in the greenhouse, and leaf number, total leaf area, and initial gas-exchange characteristics were determined for each plant. The 15 most uniform plants were selected based on total leaf area and initial gas-exchange characteristics. Selected plants were moved from the greenhouse to the walk-in plant growth chamber in the laboratory. One day before D (designated as Day-1), whole-leaf gas exchange was measured on the four most recently expanded leaves of all 15 plants proceeding from 1000 until $1200 \mathrm{HR}$. $\mathrm{R}_{\mathrm{d}}$ was measured at $2200 \mathrm{HR}$ (after $1 \mathrm{~h}$ of darkness), $0200 \mathrm{HR}$ (after $5 \mathrm{~h}$ of darkness), and $0600 \mathrm{HR}$ (after $9 \mathrm{~h}$ of darkness; $1 \mathrm{~h}$ before the lights were turned on again). On Day 0 , all 15 plants were partially defoliated between 2100 and $2200 \mathrm{HR}$. The fifth and sixth fully expanded leaves from the apex were immediately frozen in liquid $\mathrm{N}_{2}$ and stored at -80C for carbohydrate analysis to provide a Day 0 leaf carbohydrate status for each plant. On Days 0-4, gas exchange was measured beginning at 1000 HR. One of the fifteen plants was destructively harvested at each night measurement on Days 0-4. The 4 harvested leaves per plant were pooled as one sample, frozen in liquid $\mathrm{N}_{2}$, and immediately stored at $-80 \mathrm{C}$.

Leaf carbohydrate analysis. Stored leaf samples (-80C) were lyophilized, weighed, and ground in a Wiley mill to pass through a 40-mesh screen. Subsamples $(100 \mathrm{mg})$ were extracted three times each (20 rein) with $3.5 \mathrm{ml}$ of $80 \%$ ethanol. The homogenates were centrifuged at $1500 \times \mathrm{g}$ for $5 \mathrm{~min}$ after each extraction, supernatants were transferred into $50 \mathrm{ml}$ polypropylene centrifuge tubes, and $5 \mathrm{ml}$ of ultrapure water and $5 \mathrm{ml}$ of reagent grade chloroform were added to partition the chlorophyll from the sample extract. The tubes were capped, shaken vigorously, and then centrifuged at 470x g for 3 min. The upper, clear aqueous phase containing the soluble sugars was transferred to a test tube and evaporated to dryness using a rotary evaporator equipped with a refrigerated condensation trap (model RT4104) at -103C (Speedvac SC200; Savant Instruments, Farmingdale, N.Y.). The pellet was also evaporated to dryness and it, along with the soluble sugar samples, was stored in a glass desiccator over an anhydrous desiccant.

Sorbitol, glucose, fructose, and sucrose were separated and quantified by high-performance liquid chromatography (HPLC) (series 4000i system equipped with a gradient pump, CarboPac PA1 column, autosampler, and pulsed amperometric detector connected to a model 4270 integrator; Dionex Corp., Sunnyvale, Calif.). The column was eluted with ultrapure water and $200 \mathrm{~mm}$ $\mathrm{NaOH}$ that had been sonicated for 30 rein, degassed with helium for $1 \mathrm{~h}$, and then continuously degassed during the analysis. A combination of gradient and isocratic elution was used by programming the gradient pump as follows: 1) before sample injection, the column was gradient eluted with $65 \%$ water and $35 \%$ $\mathrm{NaOH} ; 2$ ) at time $=0 \mathrm{~min}$, the sample was injected and the gradient was then adjusted to $75 \%$ water and $25 \% \mathrm{NaOH}$ by time $=0.1$ rein, and the elution remained at this ratio until time $=1.5$ rein; 3) from time $=1.5 \mathrm{~min}$ to $9.0 \mathrm{~min}$ the gradient was adjusted to end up at $0 \%$ water and $100 \% \mathrm{NaOH}$; 4) from time $=9$ min to 28 rein, the column was isocratically eluted with $100 \% \mathrm{NaOH}$. The flow rate of eluent was constant at $1 \mathrm{ml} \cdot \mathrm{min}^{-1}$. The column was maintained at room temperature.

The dry sample extract was prepared for HPLC analysis by adding $1 \mathrm{ml}$ of ultrapure water, vortexing three times, each followed by at least 5 min to stand. The sample was then transferred to a $1.5-\mathrm{ml}$ Eppendorf tube and spun at $10000 \times \mathrm{g}$ for $10 \mathrm{~min}$ on a microfuge (Beckman Instruments,) to pellet any particulate matter that remained. The sample was then diluted 1:100 with ultrapure water, and a $0.5-\mathrm{ml}$ aliquot was loaded into a sample injection vial.

Table 1. The effect of partial defoliation (D) on $\mathrm{CO}_{2}$ compensation point $(\Gamma)$, estimated carboxylation efficiency $(\mathrm{k})$, net $\mathrm{CO}_{2}$ assimilation rate $\left(\mathrm{A}_{350}\right)$ and internal $\mathrm{CO}_{2}$ concentration $\left(\mathrm{C}_{\mathrm{i} 350}\right)$ at ambient $\mathrm{CO}_{2}\left(350 \mu \mathrm{l} \cdot \mathrm{liter}^{-1}\right)$, maximum A at $900 \mu \mathrm{l} \cdot \mathrm{iter}^{-1} \mathrm{CO}_{2}\left(\mathrm{~A}_{\max }\right)$, stomatal limitation to $\mathrm{A}\left(\mathrm{l}_{\mathrm{g}}\right)$, and estimated photorespiration rate $\left(\mathrm{R}_{1}\right)$ of expanded leaves of 1 -year-old, potted sour cherry trees with time. ${ }^{2}$

\begin{tabular}{|c|c|c|c|c|c|c|c|}
\hline $\begin{array}{l}\text { Lays } \\
\text { after } \\
\mathrm{D}\end{array}$ & $\begin{array}{c}\Gamma \\
(\mu \mathrm{mol} \mathrm{CO} \\
\left.\mathrm{CO}_{2} / \mathrm{mol}\right)\end{array}$ & $\begin{array}{c}\mathrm{k} \\
\left(\mathrm{mol} \mathrm{CO} / 2 / \mathrm{m}^{2} \text { per sec) }\right.\end{array}$ & $\begin{array}{c}\mathrm{A}_{350} \\
\left(\mu \mathrm{mol} \mathrm{CO} 2 / \mathrm{m}^{2} \text { per sec }\right)\end{array}$ & $\begin{array}{c}\mathrm{C}_{\mathrm{i} 350} \\
(\mu \mathrm{mol} \mathrm{CO} / \mathrm{mol})\end{array}$ & $\begin{array}{c}\mathrm{A}_{\max } \\
\left(\mu \mathrm{mol} \mathrm{CO}_{2} / \mathrm{m}^{2} \text { per sec }\right)\end{array}$ & $\begin{array}{l}\mathrm{l}_{\mathrm{g}} \\
(\%)\end{array}$ & $\begin{array}{c}\mathrm{R}_{1} \\
(\%)\end{array}$ \\
\hline 0 & 68.5 & 0.044 & 8.98 & 279 & 17.9 & 20.6 & 30.2 \\
\hline 1 & 69.5 & $0.042^{\mathrm{NS}}$ & $7.71^{\mathrm{Ns}}$ & $270^{\mathrm{NS}}$ & $21.8^{*}$ & $35.0^{* * *}$ & 27.3 \\
\hline 2 & 60.5 & $0.083^{* * *}$ & $11.35^{* *}$ & $242^{+* *}$ & $24.9^{* * * *}$ & $36.2^{* * *+}$ & 27.7 \\
\hline 3 & 66.0 & $0.075^{* * *}$ & $12.83^{* * *}$ & $261^{*}$ & $27.8^{* * *}$ & $27.1^{* *}$ & 25.3 \\
\hline 4 & 66.8 & $0.080^{* * *}$ & $13.77^{* * *}$ & $285^{\mathrm{NS}}$ & $24.4^{* * *}$ & $19.4^{\mathrm{NS}}$ & 25.5 \\
\hline 5 & 69.0 & $0.080^{* * *}$ & $13.46^{* * *}$ & $275^{\mathrm{NS}}$ & $26.0^{* * *}$ & $22.7^{\mathrm{NS}}$ & 33.1 \\
\hline 6 & 68.8 & $0.084^{* * *}$ & $13.76^{* * *}$ & $267^{\mathrm{Ns}}$ & $28.0^{* * *}$ & $25.2^{*}$ & 31.4 \\
\hline 9 & 67.3 & $0.083^{* *+4}$ & $13.48^{* * *}$ & $270^{\mathrm{NS}}$ & $26.0^{* * *}$ & $23.7^{\mathrm{NS}}$ & 25.8 \\
\hline
\end{tabular}

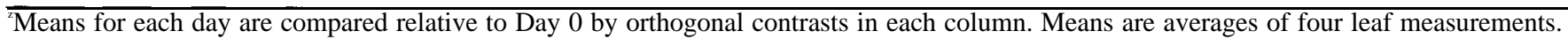

Ns ${ }^{*}, * * * * *$ Nonsignificant or significant at $P=0.05,0.01$, or 0.001 , respectively. Absence of notation indicates no significant differences among days. 
Each sample was analyzed three times. Soluble carbohydrates were identified and quantified on the basis of retention time and peak heights of known standards.

Starch in the pellet was determined using the method of Roper et al. (1988) modified as follows: samples were incubated at 55C for $16 \mathrm{~h}$ with amyloglucosidase (Boehringer Mannheim 208 469) and then assayed calorimetrically using glucose oxidase (Sigma Chemical Co.). Absorbance at $440 \mathrm{~nm}$ was read with a UV/Vis spectrophotometer. Each sample was assayed three times.

\section{Experiment 4: Short-term effects of continuous lighting}

As described above, dormant 1-year-old sour cherry trees were grown for 9 weeks in the greenhouse, and leaf number, total leaf area, and initial gas-exchange characteristics were determined for each plant. The 16 most uniform plants were selected based on total leaf area and initial gas-exchange characteristics. Selected plants were moved from the greenhouse to the walk-in plant growth chamber programmed as above. The four most uniform plants were selected for this experiment based on the combined characteristics of leaf number, total leaf area, and initial gas-exchange characteristics. Preliminary findings from Expt. 1 indicated that A of the most recently expanded leaves of control sour cherry trees, identical to those described here, was constant for at least 2 weeks in the growth chamber when trees were at this stage of development. Based on this condition, we made comparisons of the effect of $\mathrm{CL}$ on the response observed for the same leaf prior to treatment rather than comparing with separate control plants. This permitted more replications for statistically evaluating the CL effects on the same leaves over time.

Diurnal gas exchange. The fourth fully expanded leaf of each plant was inserted into an individual leaf chamber (where it remained for the duration of the experiment). The day before CL was designated as Day 0. Plants remained in CL from $0700 \mathrm{HR}$ on Day 0 until 2100 HR on Day 4. For Days 5-7, the growth chamber was reset to a 14-h photoperiod. Gas exchange was measured daily at $0900,1230,1500$, and $2000 \mathrm{HR}$. $\mathrm{CO}_{2}$ and $\mathrm{O}_{2}$ responses were measured daily between 0930 and $1430 \mathrm{HR}$ as described above.

\section{Experiment 5: Time to full photosynthetic recovery after continuous lighting}

A similar set of plants was grown for 9 weeks in the greenhouse, and leaf number, total leaf area, and initial gas-exchange charac- teristics were determined for each plant. The most uniform 15 plants were selected based on leaf number, total leaf area, and initial gas-exchange characteristics and moved to the growth chamber described above.

Five plants each were randomly selected and subjected to either 1, 2, or 3 days of CL. Recovery was followed for at least 6 days after the CL treatment. Once a given group of five plants had received the appropriate CL treatment, they were moved to the other side of the growth chamber behind a light screen at $2100 \mathrm{HR}$ and then returned to the illuminated side at $0700 \mathrm{HR}$ each day. Once all plants had received their CL treatment, the chamber was reprogrammed to a 14-h photoperiod.

On each day for the duration of the experiment, gas exchange was measured beginning at 1000 HR using the portable photosynthesis system and chlorophyll fluorescence was measured beginning at $1500 \mathrm{HR}$ (as described below). All measurements were made on the four most recently fully expanded leaves per plant. Each day after the chlorophyll fluorescence measurement, one leaf disc from each of the four leaves per plant was harvested for chlorophyll determination as described previously.

Chlorophyll fluorescence. A chlorophyll fluorescence measurement system (model CF-1000; P.K. Morgan Instruments, Andover, Mass.) was used. Leaves were dark acclimated for at least 15 min using dark acclimation cuvettes. Leaves were irradiated with $1000 \mu \mathrm{mol} \cdot \mathrm{m}^{-2} \cdot \mathrm{s}^{-1}$ PPFD actinic light and chlorophyll fluorescence kinetics were recorded over a 60-sec sample time.

\section{Results}

\section{Experiment 1}

Gas exchange over time. One day after treatment, A was 2770 higher and $48 \%$ lower than control for D and CL plants, respectively (Fig. 1A). The $\mathrm{g}_{\mathrm{s}}$ was $80 \%$ higher and $35 \%$ lower for $\mathrm{D}$ and CL plants, respectively (Fig. 1B). By 2 days after treatment, A was $47 \%$ higher and $57 \%$ lower than control for D and CL plants, respectively. The $\mathrm{g}_{\mathrm{s}} \mathrm{was}$ significantly higher in D plants (either 14or 24-h photoperiod) than in control or CL plants (Fig. 1B). $\mathrm{C}_{\mathrm{i}}$ was significantly greater for CL plants at most times of day from Day 2 on (Fig. 1C). Between 2 and 7 days after treatment, leaves from $\mathrm{D}$ and CL/D plants had significantly higher $\mathrm{A}$ and $\mathrm{g}_{\mathrm{s}}$ than controls, while CL plants had significantly lower A. The photosynthetic reduction after CL was maintained as long as plants were under CL

Table 2. Long-term effects of partial defoliation (D) on net $\mathrm{CO}_{2}$ assimilation rate (A), stomatal conductance rate (g,), leaf chlorophyll $a$, chlorophyll $b$, and protochlorophyll (P) content, and specific leaf density (SLD) of expanded leaves of 1-year-old, potted sour cherry trees. ${ }^{2}$

\begin{tabular}{|c|c|c|c|c|c|c|}
\hline Treatment & $\begin{array}{c}\mathrm{A} \\
\left(\mu \mathrm{mol} \mathrm{CO} / \mathrm{m}^{2} \text { per sec }\right)\end{array}$ & $\begin{array}{c}\mathrm{g}_{\mathrm{s}} \\
\left(\mathrm{mmol} \mathrm{CO} / \mathrm{m}^{2} \text { per sec }\right)\end{array}$ & $\begin{array}{c}\text { Chlorophyll } a \\
\left(\mu \mathrm{g} \cdot \mathrm{cm}^{-2}\right)\end{array}$ & $\begin{array}{c}\text { Chlorophyll } b \\
\left(\mu \mathrm{g} \cdot \mathrm{cm}^{-2}\right)\end{array}$ & $\begin{array}{c}\mathrm{P} \\
\left(\mu \mathrm{g} \cdot \mathrm{cm}^{-2}\right)\end{array}$ & $\begin{array}{c}\text { SLD } \\
\left(\mathrm{mg} \cdot \mathrm{cm}^{-2}\right)\end{array}$ \\
\hline \multicolumn{7}{|c|}{ II Days after $D$} \\
\hline Control & 10.4 & 75.3 & 43.9 & 18.9 & 9.9 & 9.8 \\
\hline D & 13.5 & 94.0 & 44.7 & 19.4 & 10.0 & 8.7 \\
\hline Significance & * & $*$ & NS & NS & NS & NS \\
\hline \multicolumn{7}{|c|}{23 Days after $D$} \\
\hline Control & 10.1 & 68.3 & 49.5 & 21.6 & 10.2 & 8.8 \\
\hline D & 14.1 & 137.0 & 50.0 & 21.1 & 10.3 & 9.0 \\
\hline Significance & $* *$ & $* * *$ & NS & NS & NS & NS \\
\hline \multicolumn{7}{|c|}{32 Days after $D$} \\
\hline Control & 7.9 & 48.9 & 28.9 & . 14.8 & 9.1 & 8.9 \\
\hline $\mathrm{D}$ & 13.3 & 91.3 & 44.7 & 19.7 & 9.9 & 9.5 \\
\hline Significance & $* *$ & $* *$ & $* *$ & $* *$ & $* *$ & NS \\
\hline
\end{tabular}

${ }^{\bar{T}}$ Means are averages of four replicates.

Ns,$* * * * *$ Nonsignificant or significant at $P=0.05,0.01$, or 0.001 , respectively. 
conditions. $\mathrm{A}, \mathrm{g}_{\mathrm{s}}$ and $\mathrm{C}_{\mathrm{i}}$ of control plants fluctuated diurnally and were higher at 1000 than at 1500 HR most days. After 7 days, control and CL plants were D as described above. A and $g_{s}$ steadily increased for these plants during the 5-day postdefoliation (recovery) period. $\mathrm{C}_{\mathrm{i}}$ during this recovery phase for CL plants that were $\mathrm{D}$ remained fairly constant but significantly higher than the other treatments (Fig. 1C). By 12 days after the initiation of the experiment, A was not significantly different among the treatments. The photosynthetic inhibition from CL was completely ameliorated 5 days after D.

Relationship between $A$ and $g_{s}$. Since plants from control and CL treatments were partially defoliated by Day 8, only the data for Days 1-7 were used for the regression analysis (Fig. $2 \mathrm{~A}$ and C). On the other hand, since plants from both the D and CL/D treatments were manipulated on Day 1 only, the data for Days 112 were used for the regression analysis (Fig. 2 B and D). From the regression analysis, the relationship between $A$ and $g_{s}$ over time was significant (at $P=0.05$ ) for all treatments except CL. The strongest relationship between $\mathrm{A}$ and $\mathrm{g}_{\mathrm{s}}$ was noted for leaves of control plants indicating that these leaves had the highest A per unit $\mathrm{g}_{\mathrm{s}}$ (Fig. 2A). CL led to a significant uncoupling of the relationship between $\mathrm{A}$ and $\mathrm{g}_{\mathrm{s}}$ (Fig. $2 \mathrm{C}$ and D). An analysis of covariance was performed to determine if the regression coefficients were homogeneous for the four treatments. Based on the appropriate F test, the regressions were not homogeneous.

\section{Experiment 2}

Diurnal gas exchange. A pronounced diurnal response of A and $\mathrm{g}_{\mathrm{s}}$ was observed for control and D plants in which A typically reached a maximum value at $1100 \mathrm{HR}$ and then declined in the afternoon (Fig. $3 \mathrm{~A}$ and C). One day after treatment, $\mathrm{A}$ and $\mathrm{g}_{\mathrm{s}}$ were significantly higher in the D plants at most times during the day. Between 2 and 7 days after D, A was $30 \%$ to $50 \%$ higher and $g_{s}$ was $50 \%$ to $100 \%$ higher in leaves of D plants than in leaves of control plants. $\mathrm{R}_{\mathrm{d}}$ was significantly lower (less negative) in leaves of $\mathrm{D}$ plants from 2 days after D (Fig. 3B).

Response to PPFD. A was significantly higher at each light intensity for D plants 9 days after treatment (Fig. 4). $R_{d}$ was -0.7 VS. $-0.3 \mu \mathrm{mol} \cdot \mathrm{m}^{-2} \cdot \mathrm{s}^{-1}$ for the control and D plants, respectively. The cp was 14 vs. $6 \mu \mathrm{mol} \cdot \mathrm{m}^{-2} \cdot \mathrm{s}^{-1}$ for the control and D plants, respectively. The $\phi$ was $67 \%$ higher in leaves of $\mathrm{D}$ plants than in control plants (0.0226 vs. $0.0135 \mathrm{~mol} \mathrm{CO}$ fixed/mol PPFD absorbed). Light saturation occurred near $1000 \mu \mathrm{mol} \cdot \mathrm{m}^{-2} \cdot \mathrm{s}^{-1} \mathrm{PPFD}$.

Response to $\mathrm{CO}_{2}$ and $\mathrm{O}_{2}$. A highly significant relationship was observed between $\mathrm{A}$ and $\mathrm{C}_{\mathrm{i}}$ for each date of measurement $\left(r^{2}=\right.$ 0.96, on average) (Fig. 5). The response of leaves 9 days after D was almost identical to that observed 6 days after D (Fig. 5F) and was not included in this figure. By 2 days after D, A was significantly higher at all $\mathrm{CO}_{2}$ levels. (except $70 \mu \mathrm{l} \cdot$ liter $^{-1}$ ) and this remained constant through Day 9 (data not shown). $\Gamma$ and $\mathrm{R}_{1}$ were not significantly affected by $\mathrm{D}$ (Table 1 ). Two days after $\mathrm{D}, \mathrm{k}$ was $89 \%$ higher than it was before D and it remained significantly higher on each subsequent day of measurement (Table 1 ). By 2 and 4 days after $\mathrm{D}$, net $\mathrm{CO}_{2}$ assimilation at ambient $\mathrm{CO}_{2}\left(\mathrm{~A}_{350}\right)$ was $26 \%$. and $53 \%$ higher, respectively, than it was before $\mathrm{D}$ (Table 1). B y 2 and 3 days after $\mathrm{D}$, internal $\mathrm{CO}_{2}$ concentration at ambient $\mathrm{CO}_{2}\left(\mathrm{C}_{\mathrm{i} 350}\right)$ was reduced compared to the predefoliation values but the differences were not significant by Day 4 (Table 1). A at saturating $\mathrm{CO}_{2}$ concentrations (Fig. 5) and $\mathrm{A}_{\max }$ were significantly higher after $\mathrm{D}$ (Table 1). $A_{\max }$ was $56 \%$ higher by 6 days after D (Table 1 ). The $1_{g}$ increased slightly between 1 and 3 days after D, but this was ameliorated thereafter (Table 1).

Long-term effects. A and $\mathrm{g}_{\mathrm{s}}$ remained significantly higher in leaves of D plants than in controls up to 32 days after D (Table 2). Chlorophyll $a$, chlorophyll $b$, and $\mathrm{P}$ were not significantly higher for leaves of D plants until 32 days after D. SLD was not significantly affected by $\mathrm{D}$.

\section{Experiment 3}

Respiration and leaf carbohydrate content. Leaf A increased by $30 \% 1$ day after D (Fig. 6A). By 3 or 4 days after treatment, A had almost doubled from the predefoliation value. $R_{d}$ progressively decreased (became less negative) after D (Fig. 6B). $R_{d}$ fluctuated during the dark period and was not consistently higher or lower at any given time during the night after D. Leaf starch content was significantly lower at the beginning of the night $48 \mathrm{~h}$ after $\mathrm{D}$ than

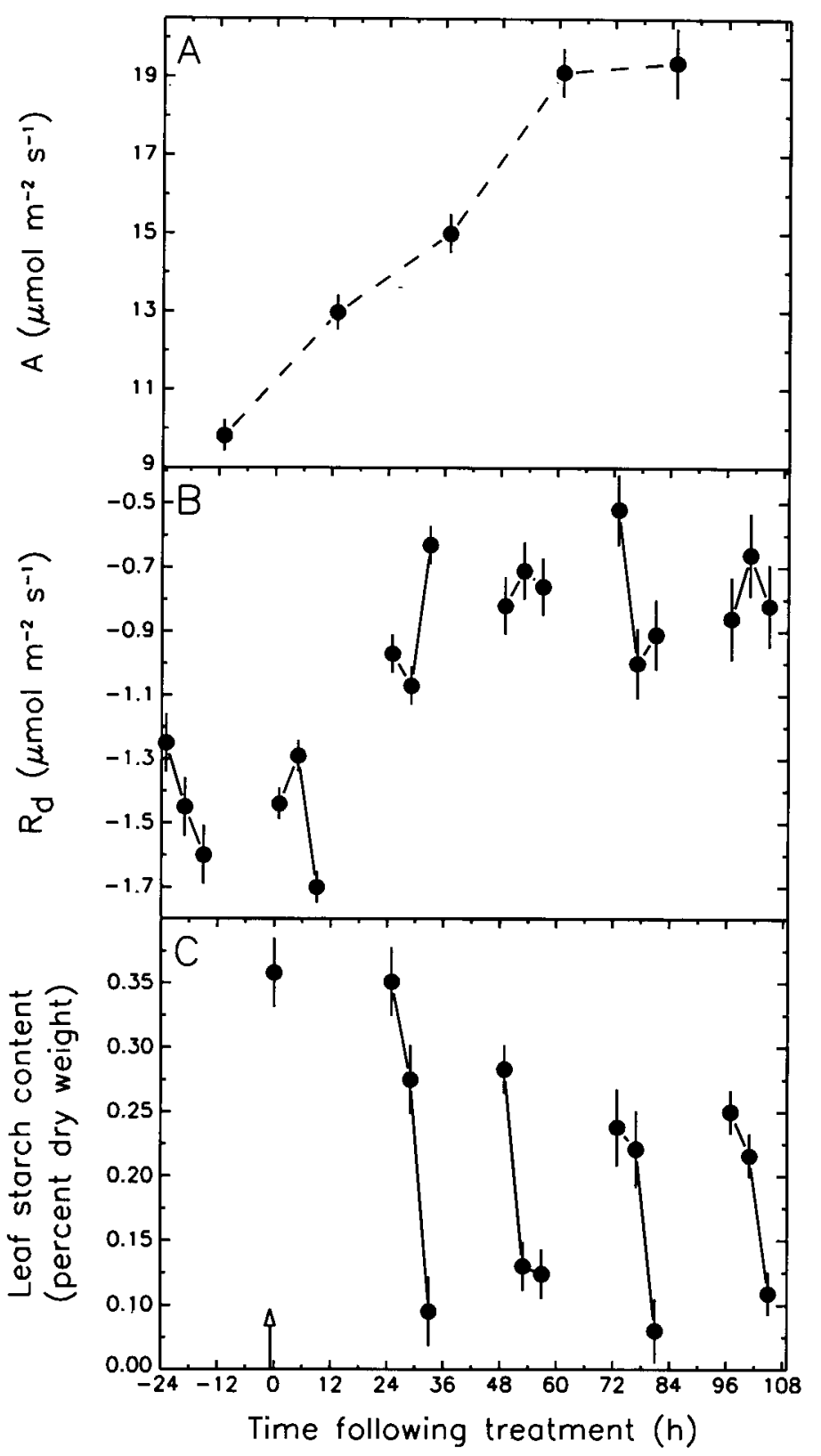

Fig. 6. Effects of partial defoliation (D) on (A) net $\mathrm{CO}_{2}$ assimilation rate (A), (B) dark respiration rate $\left(\mathrm{R}_{\mathrm{d}}\right.$, expressed as negative $\mathrm{CO}_{2}$ assimilation), and (C) leaf starch content over time for 1-year-old, potted sour cherry trees. A was measured daily at $1000 \mathrm{HR}$. $\mathrm{R}_{\mathrm{d}}$ was measured daily at 2200,0200, and $0600 \mathrm{HR}$. The arrow indicates the time at which plants were partially defoliated. Each point represents the average $( \pm \mathrm{SE})$ of at least four leaf measurements. 
it was $24 \mathrm{~h}$ earlier (Fig. 6C). Starch content was reduced by almost $40 \% 4$ days after treatment. Starch content was typically highest and lowest at the beginning and the end of the dark period, respectively. By $0600 \mathrm{HR}$, leaf starch was usually $<0.1 \%$ of the leaf dry weight. There was a significant correlation between leaf starch content and $\mathrm{R}_{\mathrm{d}}(r=-0.632)$, where leaf starch content decreased as $R_{d}$ decreased (data not shown). This reduction in $R_{d}$ after $D$ was consistently observed in four separate experiments (data not shown).

Leaf sorbitol and sucrose content increased over time after D (Table 3). Sorbitol and sucrose content was always highest and lowest at the beginning and end of the dark period, respectively. On average, soluble carbohydrates comprised about $20 \%$ of the total leaf dry weight. The relative proportions for sorbitol, glucose, fructose, and sucrose were $45 \%, 5 \%, 4 \%$, and 46\%, respectively. $\mathrm{D}$ did not significantly alter the proportionate amounts of these four major soluble carbohydrates.

\section{Experiment 4}

Diurnal gas exchange. A decreased $>2$-fold after 1 day of CL (Fig. 7A). The $\mathrm{g}_{\mathrm{s}}$ was significantly reduced by CL except at the end of Days 1 and 2 (Fig. 7B). The normal diurnal response of higher $\mathrm{A}$ and $\mathrm{g}_{\mathrm{s}}$ in the morning and lower $\mathrm{A}$ and $\mathrm{g}_{\mathrm{s}}$ in the afternoon disappeared under CL conditions (Fig. $7 \mathrm{~A}$ and B). Between 24 and $48 \mathrm{~h}$ of $\mathrm{CL}$, there was a highly significant variation in $\mathrm{g}_{\mathrm{s}}$ and $\mathrm{C}_{\mathrm{i}}$ that was dampened somewhat during the following $48 \mathrm{~h}$ (Fig. $7 \mathrm{~B}$ and C). Returning plants to a 14 -h photoperiod for 3 days was not long enough to overcome the inhibition of A resulting from 3 days of CL.

Response to $\mathrm{CO}_{2}$ and $\mathrm{O}_{2}$. A was lower at each $\mathrm{CO}_{2}$ level (except 70 and $900 \mu \mathrm{l} \cdot$ liter $^{-1} \mathrm{CO}_{2}$ ) each day in CL (Fig. $8 \mathrm{~A}-\mathrm{C}$ ) and during each of the 3 days after return to a 14-h photoperiod (Fig. 8 D-F). The relationship between $\mathrm{A}$ and $\mathrm{C}_{\mathrm{i}}$ was not as strong (based on $r^{2}$ values for the regression functions) after CL. $\Gamma$ was not altered by CL (Table 4). The $\mathrm{k}$ was reduced by almost 4 -fold after 1 day of CL and remained significantly lower (by 2-fold) even 3 days after return to a 14-h photoperiod. $\mathrm{A}_{350}$ was reduced by $>50 \%$ after 3 days of CL. $\mathrm{C}_{\mathrm{i} 350}$ was higher 1 day after CL but then not different from the pretreatment value on each subsequent day. At supraambient $\mathrm{CO}_{2}$ levels (above $350 \mu \mathrm{l} \cdot \mathrm{liter}^{-1}$ ), A was dramatically reduced for CL trees (Fig. 8 A-C). By 2 and 3 days after CL, the stomata began to present an increased limitation to A, but this was relieved after return to a 14 -h photoperiod (Table 4 ). $R_{1}$ averaged about $35 \%$ for leaves and was not significantly affected by CL (data not shown).

\section{Experiment 5}

Time to full photosynthetic recovery. After 1 day of CL, A was significantly reduced in all trees (data not shown). Exposure to 1, 2 , or 3 days of CL required 2,4, or 5 days, respectively, before A of those same leaves recovered to the rate observed before treatment (data not shown).

Chlorophyll fluorescence. Estimated photochemical efficiency (ratio of variable fluorescence $\left(\mathrm{F}_{\mathrm{v}}\right)$ to maximal fluorescence $\left(\mathrm{F}_{\mathrm{m}}\right)$, $F_{v} / F_{m}$ ) was reduced by CL (Fig. 9A). CL for 1 day inhibited $F_{v} / F_{m}$ significantly but full recovery occurred by the next day after return to a 14-h photoperiod. CL for 2 or 3 days resulted in an inhibition of $\mathrm{F}_{v} / \mathrm{F}_{\mathrm{m}}$ that took 2 to 3 days for full recovery. $\mathrm{F}$, was inhibited by CL (Fig. 9B). Instantaneous fluorescence $\left(F_{0}\right)$ decreased after 1 day in CL. By 9 days after CL exposure, $F_{v}$ and $F_{o}$ were still significantly reduced relative to the pretreatment levels. The values for $\mathrm{F}_{\mathrm{v}} / \mathrm{F}_{\mathrm{m}}$ for plants before $\mathrm{CL}(0.760$, on average) are in close agreement with the values determined for other $\mathrm{C}_{3}$ species (Bjorkman and Demmig, 1987).

change leaf chlorophyll content, or the chlorophylls to $b$ ratio (data not shown). Chlorophyll content increased slightly over time after CL. Protochlorophyll content was not altered by CL and was 1.0 $\mu \mathrm{g} \cdot \mathrm{cm}^{-2}$, on average (data not shown).

\section{Discussion}

$\mathrm{D}$ reduced the source-sink ratio in sour cherry trees and, as a result, source activity became enhanced. When enhancement of $\mathrm{A}$ occurs after D, it indicates that source leaves were operating below their maximum photosynthetic potential (Tschaplinski and Blake, 1989a). In a previous study (Layne and Flore, 1992), we found that the photosynthetic enhancement of individual leaves to leaf area reduction was due to higher estimated photochemical and car-

Table 3. The effect of partial defoliation on soluble carbohydrate content of expanded leaves of 1-year-old, potted sour cherry trees over time. ${ }^{2}$

\begin{tabular}{|c|c|c|c|c|c|c|}
\hline \multirow[b]{2}{*}{ Day } & \multirow[b]{2}{*}{ Time (HR) } & \multicolumn{5}{|c|}{ Soluble carbohydrate content $(\%$ dry wt) } \\
\hline & & Sorbitol & Glucose & Fructose & Sucrose & Total \\
\hline$\overline{0}$ & 2200 & 6.7 & 1.1 & 1.1 & 8.4 & 17.3 \\
\hline 1 & 2200 & 8.4 & 1.0 & 0.7 & 10.3 & 20.4 \\
\hline 1 & 0200 & 6.8 & 1.0 & 0.9 & 8.8 & 17.5 \\
\hline 1 & 0600 & 6.4 & 0.9 & 0.6 & 7.7 & 15.6 \\
\hline \multicolumn{2}{|c|}{ SE Day 1} & 0.2 & 0.06 & 0.05 & 0.8 & 0.9 \\
\hline 2 & 2200 & 10.7 & 1.2 & 1.2 & 10.2 & 23.3 \\
\hline 2 & 0200 & 10.7 & 0.8 & 0.7 & 9.0 & 21.2 \\
\hline 2 & 0600 & 7.6 & 0.7 & 0.7 & 7.3 & 16.3 \\
\hline \multicolumn{2}{|c|}{ SE Day 2} & 0.4 & 0.01 & 0.05 & 0.5 & 0.3 \\
\hline 3 & 2200 & 11.6 & 1.2 & 0.2 & 12.0 & 25.0 \\
\hline 3 & 0200 & 8.4 & 1.4 & 0.2 & 8.6 & 18.6 \\
\hline 3 & 0600 & 8.3 & 0.6 & 0.6 & 6.0 & 15.5 \\
\hline \multicolumn{2}{|c|}{ SE Day 3} & 0.4 & 0.01 & 0.01 & 0.1 & 0.2 \\
\hline 4 & 2200 & 11.4 & 1.2 & 1.0 & 13.1 & 26.7 \\
\hline 4 & 0200 & 10.0 & 1.2 & 0.6 & 10.6 & 22.4 \\
\hline 4 & 0600 & 9.3 & 1.2 & 0.8 & 8.1 & 19.4 \\
\hline \multicolumn{2}{|c|}{ SE Day 4} & 0.3 & 0.04 & 0.10 & 0.4 & 0.4 \\
\hline
\end{tabular}

${ }^{2}$ Data are means of three subsamples per sample. SES apply to the means for each day, respectively. 


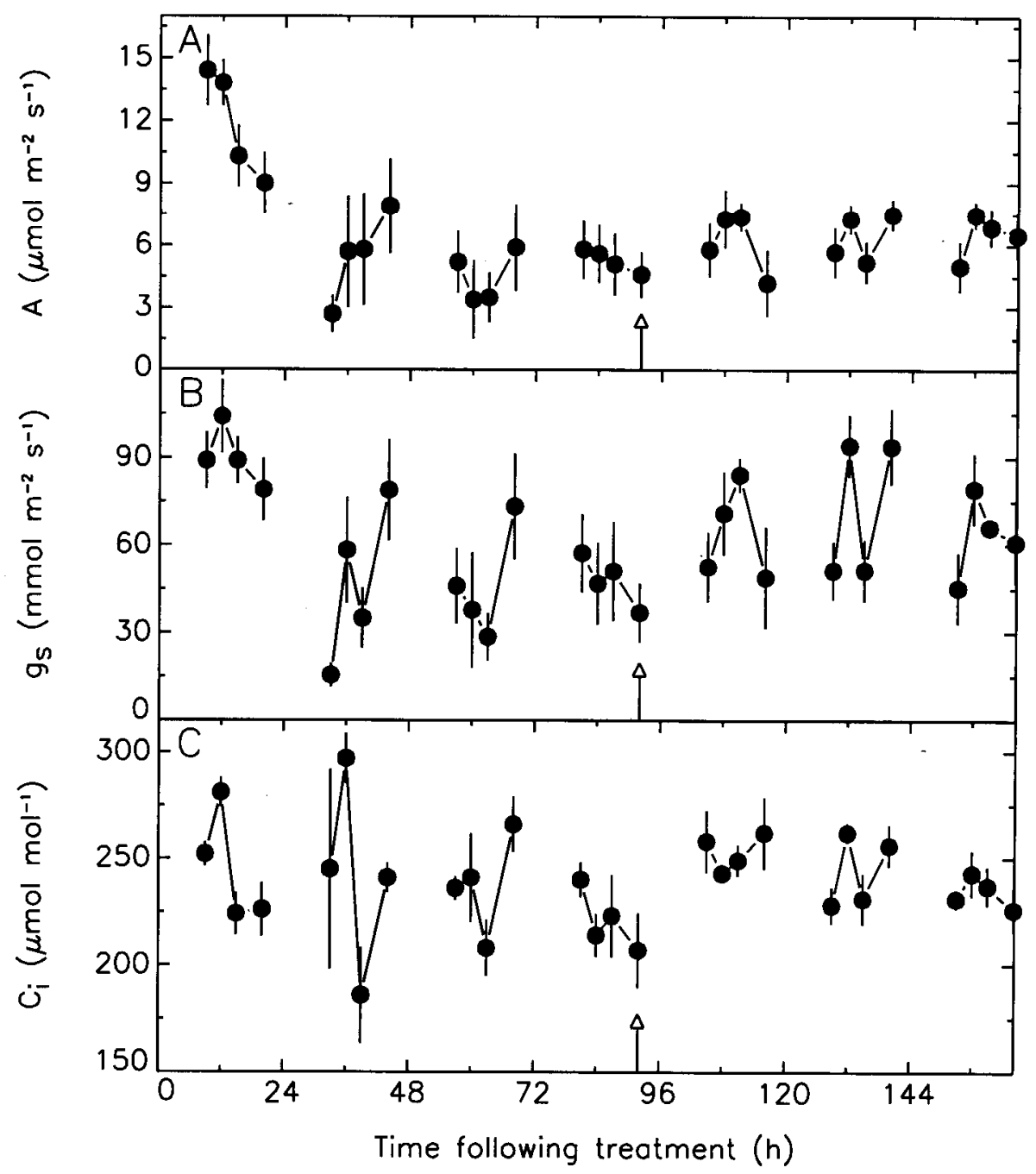

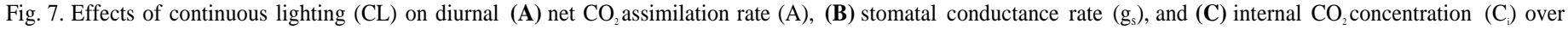

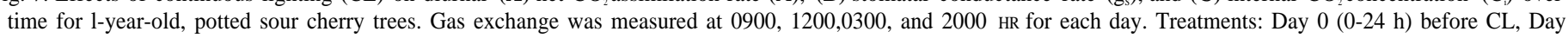

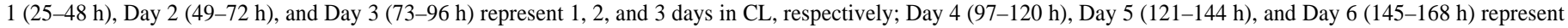

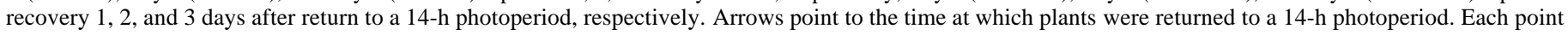
represents the average $( \pm \mathrm{SE})$ of four leaf measurements.

boxylation efficiencies and $\mathrm{RuBP}$ regeneration rate, and we suggest that a similar short-term mechanism is involved in source leaves of D plants noted here. Enhanced $g_{s}$ also contributed to the photosynthetic enhancement that was observed. Tschaplinski and Blake (1989a) found a similar increase in A and $\mathrm{g}_{\mathrm{s}}$ after decapitation of Populus trees. DeJong (1986) concluded that the higher photosynthetic rate of fruiting peach trees vs. those that had been defruited early in the season was due to enhanced $g_{s}$. Although we present evidence for a higher estimated carboxylation efficiency and stomatal conductance associated with D, Hudson et al. (1992) suggest that stomatal function is independent of total leaf rubisco activity. The enhancement of A was clearly not due to a reduced oxygenase activity of rubisco since $\mathrm{R}_{1}$ was not affected by defoliation.

Tschaplinski and Blake (1989b) suggested that carbohydrate reserves in the stems of decapitated Populus trees played an important role in buffering short-term responses to altered sink demand. In our sour cherry trees, A was enhanced within $24 \mathrm{~h}$ of D. If the argument of Tschaplinski and Blake (1989b) applied to these young, potted sour cherry trees, then the reserve carbohydrate supply in their stems was small and it was rapidly depleted. Photosynthetic enhancement and senescence delay may continue for weeks or months after D until a sink-limiting condition develops (Satoh et al., 1977). Reduced chlorophyll degradation, or enhanced synthesis may partly account for the short-term enhancement of@ that was observed, but the long-term, sustained enhancement of A after D may have been due to the increased production of chloroplasts (Woolhouse, 1967) and plastid proteins (Wareing et al. 1968) and a reduced competition for root-derived cytokinin (Satoh et al., 1977; Wareing et al., 1968).

The diurnal A response of individual leaves of plants under a constant light intensity in a growth chamber was similar to that observed in peach (Moing et al., 1992) or for whole trees measured outside in a whole-plant chamber under natural illumination conditions (Sams and Flore, 1983). The photosynthetic rates observed in this experiment were lower than that of field grown cherry trees (as reported in Sams and Flore, 1982). There are two possible explanations for this apparent discrepancy: 1) our trees were not grown outside but rather in the greenhouse and growth chamber and leaves were more typical of shade leaves in terms of morphology and A (Flore and Sams, 1986); and 2) we removed lateral shoots from the trees as they developed thereby reducing the number of competing sinks. The linear relationship between A and 
$\mathrm{g}_{\mathrm{s}}$ that we observed in sour cherry has been observed in several other tree crops including apple (Lakso, 1979), Cacao (Joly and Hahn, 1989) and Populus (Liu and Dickmann, 1992). Since this A vs. $g_{s}$ relationship was quite strong throughout the diurnal photoperiod, the decline in A was due, in part, to a similar decline in $\mathrm{g}_{s}$. Tschaplinski and Blake (1989a) noted similar diurnal responses of $\mathrm{A}$ and relationships between $\mathrm{A}$ and $\mathrm{g}_{\mathrm{s}}$ for rejuvenated stump leaves of decapitated Populus plants. Although Loveys et al. (1987) found that abscisic acid was relatively unimportant in the control of $\mathrm{g}_{\mathrm{s}}$ in apricot ( $P$. armeniaca L.), the possibility of a mild water stress induced stomatal closure in the afternoon cannot be completely tiled out since abscisic acid concentration and leaf water potential were not measured. The trees in this experiment were watered regularly and exhibited no visual symptoms of water stress. Similar trees in another study (Layne and Flore, 1993) exhibited no change in leaf xylem water potential after D. It is currently not known whether plants of the genus Prunus contain a tight-binding inhibitor of rubisco (Seemann et al., 1985) that may lead to partial rubisco deactivation in the afternoon. But since gasexchange measurements were made at or near a saturating light intensity, the deactivation of rubisco by carboxyarabinitol-1phosphate appears unlikely (Berry et al., 1987).

$\mathrm{D}$ not only resulted in a significant enhancement of $\mathrm{A}$, but carbon pools were significantly altered such that the relative

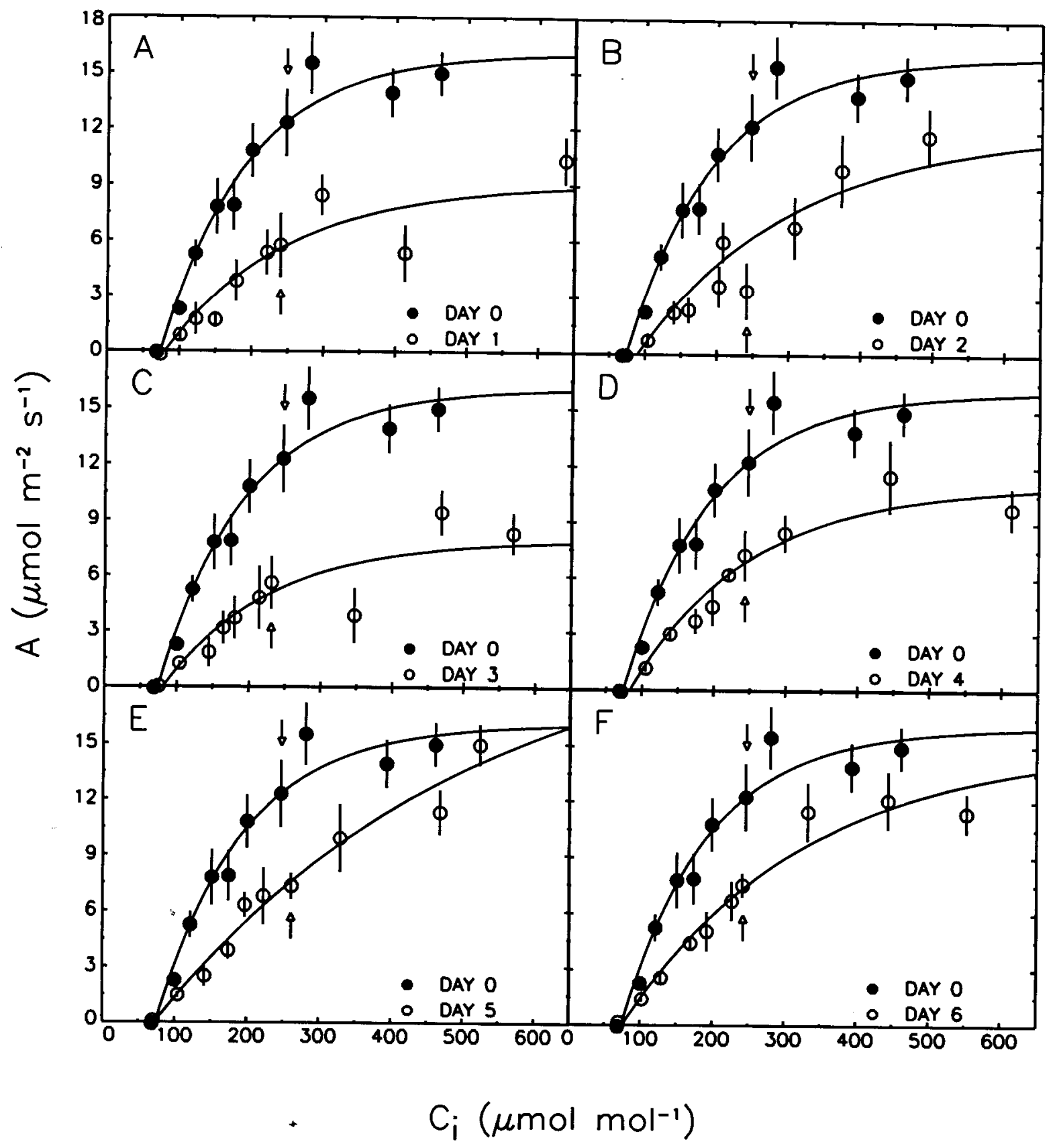

Fig. 8. Effect of continuous lighting (CL) on the response over time of net $\mathrm{CO}_{2}$ assimilation rate (A) to internal $\mathrm{CO}_{2}$ concentration $\left(\mathrm{C}_{\mathrm{i}}\right)$ of 1-year-old, potted sour cherrPy trees. Each section (A-F) compares the Day 0 pretreatment response (0) with the treatment response for the subsequent day $(O)$. Treatments: Day $0=$ before CL; Days 1 (A), 2 (B), and 3 (C) represent 1,2, and 3 days in CL, respectively; Days 4 (D), 5 (E), and 6 (F) represent recovery 1,2, and 3 days after return to a 14-h photoperiod, respectively. Regression lines occur about the data. Arrows point to the data collected at ambient $\mathrm{CO}_{2}$ partial pressure $\left(350 \pm 25 \mu \mathrm{l} \cdot\right.$ liter $\left.{ }^{-1}\right)$. Data points that represent the average $( \pm \mathrm{SE})$ of four leaf measurements appear about the regressions. 
proportions of storage carbohydrate (starch) decreased while transport carbohydrates (sucrose and sorbitol) increased in the source leaf. Enhanced degradation of leaf starch may have provided additional substrates (e.g., glucose-6-phosphate, Glc-6-P) and, coupled with the enhancement of A noted, leaf sorbitol and sucrose biosynthesis may have exceeded the rate of export from the leaf leading to accumulation and a subsequent photosynthetic inhibition. This would indicate that, in the afternoon, trees were sinklimited. To our knowledge, there are no reports of Glc-6-P or sorbitol being directly involved in end-product inhibition of photosynthesis, but Moing et al. (1992) suggested that sorbitol biosynthesis is probably subject to a similar fine control mechanism as exists for sucrose biosynthesis. Although sorbitol accumulation has been associated with osmotic adjustment to short-term drought stress (Bieleski, 1982; Ranney et al., 1991) we did not observe any effect of D on leaf water potential (Layne and Flore, 1993). Direct inhibition of the rate of sucrose synthesis from sucrose accumulation in the cytosol has been suggested as a possible mechanism of feedback inhibition (Herold, 1980), yet Foyer (1988) has suggested that modulation of sucrose phosphate synthase activity occurs by an intermediate component (e.g., glucose, fructose) rather than by sucrose, per se. In contrast to the report of Stitt et al. (1990), where sucrose and starch accumulated in feedback-inhibited leaves, under our conditions, as sucrose content increased, starch content actually decreased overtime. In addition, thylakoid reactions, as estimated by chlorophyll fluorescence parameters, were not adversely affected by D (Layne and Flore, 1993).

The reduced $\mathrm{R}_{\mathrm{d}}$ coupled with low starch concentrations indicated that leaves of $\mathrm{D}$ plants may have been substrate limited for mitochondrial respiration in the night. The variability of $R_{d}$ during the dark period indicated that factors in addition to starch content were also involved in $\mathrm{R}_{\mathrm{d}}$ noted. Avery et al. (1979) noted similar effects of $D$ on potted apple trees, where $A$ and $R_{d}$ were related to substrate concentrations. Although we did not measure export rate, the fact that $A$ increased while $R_{d}$ decreased indicates that transport from the leaf probably increased after D (Avery et al., 1979). Avery et al. ( 1979) further suggested that A was modulated by removal of carbohydrates from the leaf and that there was a negative feedback mechanism via the phloem-transport system. Fondy and Geiger (1982) suggested that starch accumulation and degradation in source leaves of Beta vulgaris L. was controlled exogenously by the leaf sucrose concentration and endogenously by the photoperiod or photosynthetic duration. Mullen and Keller (1988) noted that the rate of assimilate export during the night for soybean leaves was closely associated with the rate of starch mobilization but not closely related with either leaf sucrose content or respira- tory $\mathrm{CO}_{2}$ loss. They further noted that starch stopped accumulating before the end of the light period and that there was a 75-min delay before starch was mobilized in the dark. It is possible that some of the depletion in leaf starch overtime was due to mobilization in the light as has been observed in cottonwood (Dickson and Larson, 1975).

CL altered the source-sink balance in sour cherry trees and led to an inhibition of leaf photosynthesis. Photosynthetic inhibition from CL has been observed in apple (Bohning, 1949) and sour cherry (Layne and Flore, 1993). Most of the decline in A after CL was from an increased mesophyll limitation as indicated by the significant decline in estimated carboxylation efficiency and RuBP regeneration rate. Although the stomatal limitation to $\mathrm{A}$ increased slightly as the duration of exposure to CL increased, $\mathrm{C}_{\mathrm{i}}$ was not significantly reduced. Stomatal function has been found to be independent of total leaf rubisco activity (Hudson et al., 1992) and, hence, the physiological consequence of reduced $\mathrm{g}_{\mathrm{s}}$ appeared to be negligible under CL conditions. Unlike our control trees in this experiment, or apple trees exposed to varying water stresses (Lakso, 1979), the linear relationship between $\mathrm{A}$ and $\mathrm{g}_{\mathrm{s}}$ became uncoupled, indicating that A was not primarily limited by $g_{s}$ under CL.

CL may have increased the mesophyll limitation to photosynthesis through one or a combination of the following mechanisms: 1) feedback inhibition (Foyer, 1988), 2) photoinhibition, or 3) photooxidation (Powles, 1984). Assuming that sink demand remained unchanged under CL, it is likely that the increase in photosynthesis duration resulted in a sink-limiting condition (Sawada et al. 1989). According to Furbank et al. (1987), a stromal orthophosphate $\left(\mathrm{P}_{\mathrm{i}}\right)$ limitation may have occurred under sinklimiting conditions whereby chloroplast metabolism was restrained by limiting stromal and thylakoid reactions. In support of a $\mathrm{P}_{\mathrm{i}}$ limiting condition, we found that leaf starch content significantly increased while sucrose and sorbitol pool concentrations actually decreased while plants were under CL (Layne and Flore, 1993). Since the concentration of soluble carbohydrates in the cytosol decreased under CL (Layne and Flore, 1993), it is unlikely that leaves were feedback inhibited by sucrose, per se (Foyer, 1988). On the other hand, starch accumulation in the chloroplast has been associated with an inhibition of A (Gucci et al., 1991a, 1991 b). It is possible that starch mobilization in the light (Dickson and Larson, 1975) was at such a low rate that starch accumulated to inhibitory concentrations causing one or more of the following to occur: 1) starch binding of $\mathrm{Mg}^{2+}$ required for rubisco activation (Plaut et al., 1987); 2) starch grain obstruction of the light path to the thylakoid membrane (Warren Wilson, 1966); 3) increasing the

Table 4. The effect of continuous lighting on $\mathrm{CO}_{2}$ compensation point $(\Gamma)$, carboxylation efficiency $(\mathrm{k})$, net $\mathrm{CO}_{2}$ assimilation rate $\left(\mathrm{A}_{350}\right)$, and internal $\mathrm{CO}_{2}$ concentration $\left(\mathrm{C}_{\mathrm{i} 350}\right)$ at ambient $\mathrm{CO}_{2}\left(350 \mu \mathrm{l} \cdot\right.$ liter $\left.{ }^{-1}\right)$, and stomata] limitation to A $\left(1_{\mathrm{g}}\right)$ of expanded leaves of 1 -year-old, potted sour cherry trees with time.'

\begin{tabular}{|c|c|c|c|c|c|c|c|}
\hline Day & $\begin{array}{c}\text { Dark }^{y} \\
\text { (h) }\end{array}$ & $\begin{array}{l}\text { Light } \\
\text { (h) }\end{array}$ & $\begin{array}{c}\Gamma \\
(\mu \mathrm{mol} \mathrm{CO} / \mathrm{mol})\end{array}$ & $\begin{array}{c}\mathrm{k} \\
\left(\mathrm{mol} \mathrm{CO} 2 / \mathrm{m}^{2} \text { per sec) }\right.\end{array}$ & $\begin{array}{c}\mathrm{A}_{350} \\
\left(\mu \mathrm{mol} \mathrm{CO} / \mathrm{m}^{2} \text { per sec }\right)\end{array}$ & $\begin{array}{c}\mathrm{C}_{\mathrm{i} 350} \\
(\mu \mathrm{mol} \mathrm{CO} / \mathrm{mol})\end{array}$ & $\begin{array}{c}1_{g} \\
(\%)\end{array}$ \\
\hline$\overline{0}$ & 10 & 14 & 75.3 & 0.088 & 12.28 & 246.8 & 11.0 \\
\hline 1 & 0 & 24 & 79.8 & $0.019^{* * *}$ & $5.72^{* *}$ & $296.7^{* *}$ & $18.2^{\mathrm{NS}}$ \\
\hline 3 & 0 & 24 & 79.0 & $0.026^{* * *}$ & $5.60^{* *}$ & $214.3^{\mathrm{NS}}$ & $30.5^{*}$ \\
\hline 4 & 10 & 14 & 81.0 & $0.040^{* * *}$ & $7.26^{*}$ & $242.5^{\mathrm{NS}}$ & $27.3^{\mathrm{NS}}$ \\
\hline
\end{tabular}

${ }^{2}$ Means for each day are compared relative to Day 0 by orthogonal contrasts in each column. Means are averages of four replicates.

'Dark and Light correspond to the number of hours in darkness and light during a $24 \mathrm{~h}$ cycle.

ns $* * * * * *$ Nonsignificant or significant at $P=0.05,0.01$, or 0.001 , respectively. Absence of notation indicates no significant differences among days. 
diffusive path length or interfering with intercellular $\mathrm{CO}_{2}$ transport (Nafziger and Keller, 1976); or 4) physical damage to chloroplasts (Schaffer et al., 1986; Wildman, 1967).
Thylakoid reactions including light trapping, electron transport, and ATP production via ATP synthase were probably limited under $\mathrm{CL}$ as indicated by the reduced $\mathrm{F}_{\mathrm{v}} / \mathrm{F}_{\mathrm{m}}$ and estimated $\mathrm{RuBP}$

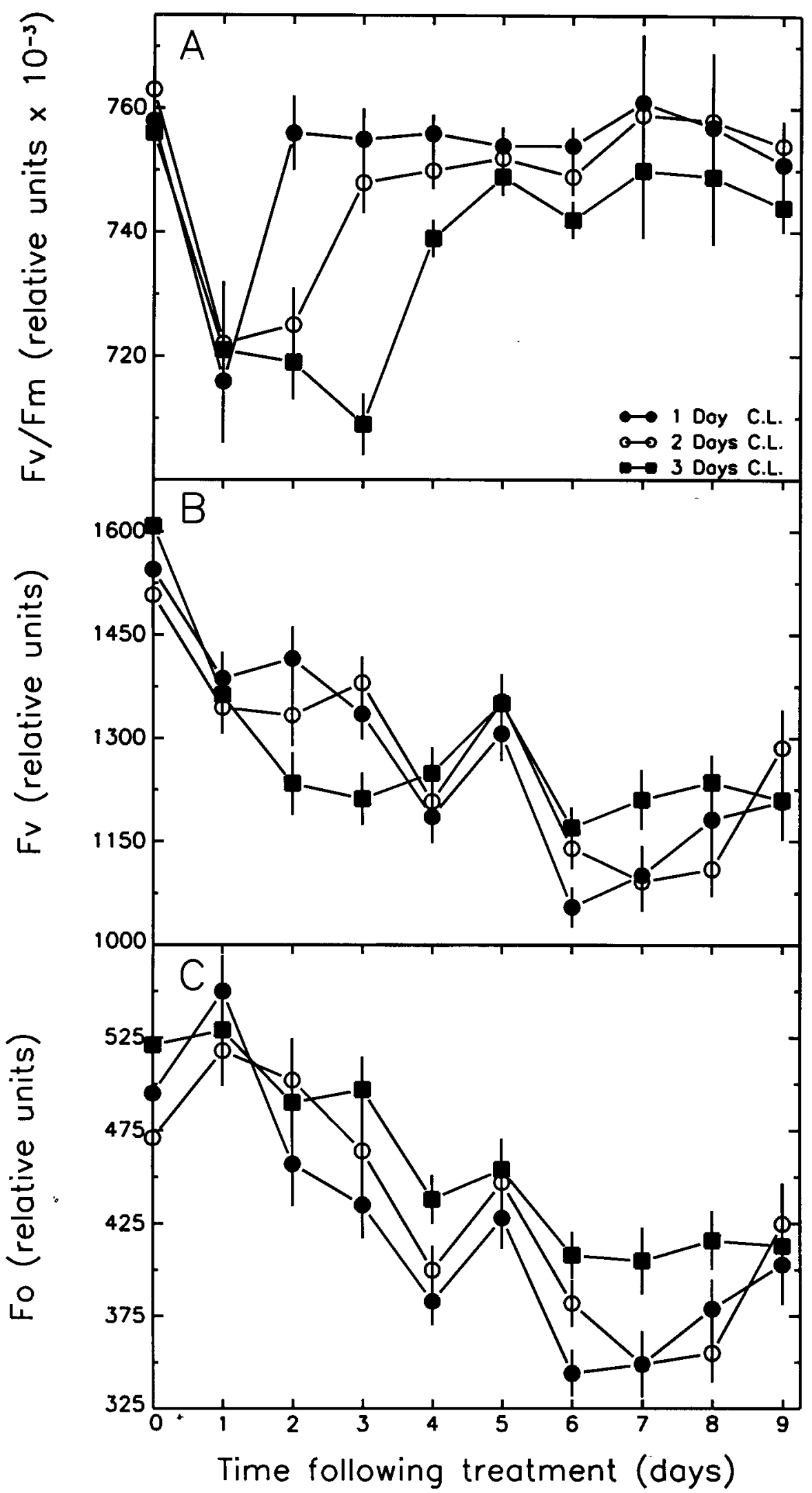

Fig. 9. Time course for the response of $(A)$ estimated photochemical efficiency $\left(F_{v} / F_{m}\right),(B)$ variable fluorescence $\left(F_{v}\right)$, and $(C)$ instantaneous fluorescence $\left(F_{o}\right)$ to continuous lighting $(C L)$ in 1-year-old, potted sour cherry trees. Treatments: $1(\bullet), 2(\mathrm{O})$, and $3(\boldsymbol{\square})$ days in CL, respectively. Chlorophyll fluorescence was measured daily beginning at $1500 \mathrm{HR}$. Each point represents the average $( \pm \mathrm{SE})$ of 20 leaf measurements. 
regeneration rate. $\mathrm{A} \mathrm{P}_{\mathrm{i}}$ limitation in the chloroplast stroma should decrease the ATP : ADP ratio and depress the reduction of 3phosphoglycerate and the regeneration of RuBP (Robinson and Walker, 198 1). Since A and carboxylation efficiency were significantly inhibited under CL, substrate RuBP concentrations may have limited carboxylation as well. The Pi requirement of chloroplasts varies with $\mathrm{O}_{2}$ pressure (Usuda and Edwards, 1982) and decreasing oxygenation (by decreasing $\mathrm{O}_{2}$ pressure) lowers A by making Pi less available (Sharkey, 1985). We did not observe $\mathrm{O}_{2}$ insensitivity of A upon exposure to low $\mathrm{O}_{2}$ (Sharkey, 1985) but we measured the low $0_{2}$ response at significantly higher leaf temperatures (28C) than those reported by Sage and Sharkey ( 1987) where $\mathrm{O}_{2}$ sensitivity was observed. To definitively verify whether $\mathrm{Pi}$ was limiting in the stroma or cytosol of feedback-limited leaves, nonaqueous fractionation techniques could be used (Sharkey and Vanderveer, 1989).

Photoinhibition, which precedes chlorophyll bleaching or photooxidation (Powles, 1984), also contributed to the decline in A under CL. Karukstis (1991) stated that photoinhibition of photosynthesis is manifested at the leaf, thylakoid, and photosystem II level by losses in $\mathrm{CO}_{2}$ fixation, electron transport capacity, and $\mathrm{F}_{v}$, respectively. Indeed, according to these conditions, sour cherry leaves exposed to CL were photoinhibited. Like Williams and Farrar (1988) using barley, we noted in cherry that as CL duration increased, the amount of reduction in F, increased. Since the observed photoinhibition resulted in a decrease in $\mathrm{F}_{0}$ overtime, this indicated that there was a reversible regulatory mechanism whereby the damage to photosystem II centers could be repaired (Krause, 1988). The restoration of $F_{v} / F_{m}$ after return to a 14-h photoperiod in cherry leaves indicated that recovery from photoinhibition had indeed occurred (Krause, 1988). In studies on citrus, starch accumulation led to leaf chlorosis, senescence, and disruption of thylakoid membranes (Schaffer et al., 1986). Although there was a significant increase in leaf starch content during CL, up to $1.5 \%$ dry weight (Layne and Flore, 1993), we did not observe an effect of CL on leaf chlorophyll content. We assume that photooxidation did not occur in these experiments since no leaf chlorosis or necrosis was observed during 7 days of CL. If photooxidative damage did occur, it appears that the rate of damage did not exceed the rate of repair (Kyle, 1987). The full photosynthetic recovery after defoliation of CL plants may have been due to relief of endproduct inhibition by depletion of accumulated starch (Sasek et al., 1985), reduced competition for root derived cytokinins (Satoh et al., 1977; Wareing et al., 1968) and/or production of new photosynthetic machinery (Satoh et al., 1977). Photosynthetic inhibition was not observed in partially defoliated plants that were continuously illuminated. It is possible that the export rate from source leaves to sinks may have been high enough to prevent carbohydrate accumulation under these conditions (Tschaplinski and Blake, 1989b).

The model plant system was used so that plant uniformity could be attained, environmental conditions could be precisely regulated, and consistent experimental manipulations could be achieved. We hoped thereby to eliminate the likely confounding effects that would occur in the field (weather, yield inconsistency, etc.). Use of a model plant system for detailed physiological studies that are difficult or impossible in the field is not without drawbacks. While maintaining source-sink uniformity in plant material, controlling environmental conditions, and ensuring that biotic or abiotic stress conditions did not confound the experiment, a compromise was made in being able to extrapolate these findings to how mature, fruiting trees would respond in the field (Gucci, 1988). By training trees to a single shoot for uniformity and utilization of walk-in, plant growth chambers, we may have predisposed trees to a sinklimiting condition (Layne and Flore, 1993). In future studies, it would be desirable to allow a significant number of competing sinks (developing shoots) to develop to ensure that sink-limited conditions did not occur. Whether plants such as those just described would demonstrate a diurnal decline in A after D is not known. With the recent development of inflatable balloons for whole-tree gas-exchange measurements (Corelli-Grappadelli and Magnanini, 1993) and new gas-exchange equipment that can now be used in the field for the development of $\mathrm{CO}_{2}$, light, and VPD responses, more detailed physiological data can be collected in the field than before. Thus, whole-tree responses to source-sink alterations can be accurately monitored for mature, fruiting trees and the phenomenon and implications of end-product inhibition of A can be thoroughly investigated in the orchard.

In conclusion, under certain conditions, sink demand limits photosynthesis in young, potted sour cherry trees through the efficiency of photoassimilate production and use (Foyer, 1988). Manipulating whole plants to alter the source-sink ratio enabled us to investigate the possible mechanisms involved in the endproduct regulation of photosynthesis in young, potted trees. Both whole-plant manipulation techniques that we used resulted in conditions where A was inhibited but the mechanism of action was probably different. The diurnal decline in A for D plants was associated with an increase in leaf sucrose and sorbitol content and a reduction in leaf starch indicating that. in the afternoon. trees were sink limited, and that sucrose and/or sorbitol were likely involved in the inhibition noted. We are currently unaware of any other reports linking leaf sorbitol content to an inhibition of source leaf A. Thylakoid reactions were not adversely affected by D. On the other hand, the decline in A after exposure to CL was in part due to photoinhibition and an accumulation of leaf starch (Layne and Flore, 1993). Whether chloroplasts became engorged with starch grains such that the thylakoid membrane became disrupted and electron transport through photosystem II was adversely affected as suggested by Wildman ( 1967) remains equivocal. Responses to CL also indicated that a $\mathrm{P}_{\mathrm{i}}$ limitation existed but actual $\mathrm{P}_{\mathrm{i}}$ concentrations were not determined. Finally, sour cherry A is affected by assimilate concentrations in the leaf. The precise points of regulation in the pathways to production of starch, sucrose, and sorbitol under sink-limiting conditions need to be determined.

\section{Literature Cited}

Aoki, S. 1981. Effects of plucking of young tea plants on their photosynthetic capacities in the mature and overwintered leaves. Jpn. J. Crop. Sci 50:445-451.

Avery, D.J., C.A. Preistley, and K.J. Treharne. 1979. Integration of assimilation and carbohydrate utilization in apple, p. 221-231. In: R. Marcelle, H. Clijsters, and M. Van Poucke (eds.). Photosynthesis and plant development. Junk Publishers, The Hague.

Baysdorfer, C. and J.A. Bassham. 1985. Photosynthate supply and utilization in alfalfa. A developmental shift from a source to a sink limitation of photosynthesis. Plant Physiol. 77:313-3 17.

Berry, J. A., G.H. Lorimer, J. Pierce, J.R. Seemann, J. Meek, and S. Freas. 1987. Isolation, identification, and synthesis of 2-carboxyarabinitol-1phosphate, a diurnal regulator of ribulose bisphosphate carboxylase activity. Proc. Natl. Acad. Sci. 84:734-738.

Bieleski, R.L. 1982. Sugar alcohols, p. 158-192. In: F.A. Loemus and W. Tanner (eds.). Encyclopedia of plant physiology. new series. vol. 13A. Springer-Verlag, Berlin.

Bjorkman, O. and B. Demmig. 1987. Photon yield of $\mathrm{O}_{2}$ evolution and chlorophyll fluorescence characteristics at $77 \mathrm{~K}$ among vascular plants of diverse origins. Planta 170:489-504.

Bohning, R.H. 1949. Time course of photosynthesis in apple leaves 
exposed to continuous illumination. Plant Physiol. 24:222-240.

Corelli-Grappadelli, L. and E. Magnanini. 1993. A whole-tree system for gas-exchange studies. HortScience 28:41-45.

DeJong, T.M. 1986. Fruit effects on photosynthesis in Prunus persica. Physiol. Plant. 66: 149-153.

Dickson, R.E. and P.R. Larson. 1975. Incorporation of ${ }^{14}$ C-photosynthate into major chemical fractions of source and sink leaves of cottonwood. Plant Physiol. 56: 185-193.

Farquhar, G.D. and T.D. Sharkey. 1982. Stomatal conductance and photosynthesis. Annu. Rev. Plant Physiol. 33:317-345.

Flore, J.A. and D.R. Layne. 1995. Photoassimilate distribution in Prunus. In: E. Zamski and A.A. Schaeffer (eds.). Photoassimilate distribution in plants and crops: Source-sink relationships. Marcel Dekker, New York. (In press.)

Flore, J.A. and C.E. Sams. 1986. Does photosynthesis limit yield of sour cherry (Prunus cerasus) 'Montmorency'? In: A.N. Lakso and F. Lenz (eds.). The regulation of photosynthesis in fruit trees. Symp. Proc. Publ. New York State Agr. Expt. Sta., Geneva.

Fondy, B.R. and D.R. Geiger. 1982. Diurnal pattern of translocation and carbohydrate metabolism in source leaves of Beta vulgaris L. Plant Physiol. 70:671-676.

Foyer, C.H. 1988. Feedback inhibition of photosynthesis through sourcesink regulation in leaves. Plant Physiol. Biochem. 26:483-492.

Furbank, R. T., C.H. Foyer, and D.A. Walker. 1987. Regulation of photosynthesis in isolated spinach chloroplasts during orthophosphate limitation. Biochem. Biophys. Acta 894:649-658.

Gucci, R. 1988. The effect of fruit removal on leaf photosynthesis, water relations, and carbon partitioning in sour cherry and plum. PhD diss. Michigan State Univ., East Lansing.

Gucci, R., P.D. Petracek, and J.A. Flore. 1991 a. The effect of fruit harvest on photosynthetic rate, starch content, and chloroplast ultrastructure in leaves of Prunus avium L. Adv. Hort. Sci. 5;19-22.

Gucci, R., C. Xiloyannis, and J.A. Flore. 199 lb. Gas exchange parameters, water relations and carbohydrate partitioning in leaves of fieldgrown Prunus domestica following fruit removal. Physiol. Plant. 83:497505.

Herold, A. 1980. Regulation of photosynthesis by sink activity-The missing link. New Phytol. 86:13 1-144.

Hudson, G. S., J.R. Evans, S. Von Caemmerer, Y.B.C. Arvidsson, and T.J. Andrews. 1992. Reduction of ribulose-1,5-bisphosphate carboxylase/ oxygenase content by antisense RNA reduces photosynthesis in transgenic tobacco plants. Plant Physiol. 98:294-302.

Hunt, R. 1980. Asymptotic functions, p. 121-146. In: Plant growth curves. Univ. Park Press, Baltimore.

Joly, R.J. and D.T. Hahn. 1989. Net $\mathrm{CO}_{2}$ assimilation of cacao seedlings during periods of plant water deficit. Photosyn. Res. 21:151-159.

Jones, H.G. 1985. Partitioning stomatal and non-stomatal limitations to photosynthesis. Plant Cell Environ. 8:95-104.

Kappes, E.M. 1985. Carbohydrate production, balance, and transpiration in leaves, shoots and fruits of 'Montmorency' sour cherry. PhD diss. Michigan State Univ., E. Lansing. (Abstr. 86-13300.)

Karukstis, K.K. 1991. Chlorophyll fluorescence as a physiological probe to the photosynthetic apparatus, p. 769-795. In: H. Sheer (cd.). Chlorophylls. CRC Press, Boca Raton, Fla..

Krause, G.H. 1988. Photoinhibition of photosynthesis. An evaluation of damaging and protective mechanisms. Physiol. Plant. 74:566-574.

Kyle, D.J. 1987. The biochemical basis for photoinhibition of photosystem II, p. 197-226. In: D.J. Kyle, C.B. Osmond, and C.J. Amtzen (eds.). Photoinhibition. Elsevier, Amsterdam.

Lakso, A.N. 1979. Seasonal changes in stomatal response to leaf water potential in apple. J. Amer. Soc. Hort. Sci. 104:58-60.

Layne, D.R. and J.A. Flore. 1992. Photosynthetic compensation to partial leaf area reduction in sour cherry. J. Amer. Soc. Hort. Sci. 117:279-286. Layne, D.R. and J.A. Flore. 1993. Physiological responses of Prunus cerasus L. to whole-plant source manipulation. Leaf gas exchange, chlorophyll fluorescence, water relations and carbohydrate concentrations. Physiol. Plant. 88:44-51.

Liu, Z. and D.I. Dickmann. 1992. Abscisic acid accumulation in leaves of two contrasting hybrid poplar clones affected by nitrogen fertilization plus cyclic flooding and soil drying. Tree Physiol. 11:109-122.

Loescher, W.H. 1987. Physiology and metabolism of sugar alcohols in higher plants. Physiol. Plant. 70:553-557.

Loveys, B. R., S.P. Robinson, and W.J.S. Downton. 1987. Seasonal and diurnal changes in abscisic acid and water relations of apricot leaves (Prunus armeniaca L.). New Phytol. 107:15-27.

Moing, A., F. Carbonne, M.H. Rashad, and J.-P. Gaudillère. 1992. Carbon fluxes in mature peach leaves. Plant Physiol. 100:1878-1884.

Moon, J. W., Jr and J.A. Flore. 1986. A BASIC computer program for calculation of photosynthesis, stomatal conductance, and related parameters in an open gas exchange system. Photosynth. Res. 7:269-279.

Moran, R. 1982. Formulae for determination of chlorophyllous pigments extracted with n,n-dimethylformamide. Plant Physiol. 69:1376-1381.

Mullen, J.A. and H.R. Keller. 1988. Trends in carbohydrate depletion, respiratory carbon loss, and assimilate export from soybean leaves at night. Plant Physiol. 86:517-521.

Nafziger, E.D. and H.R. Keller. 1976. Influence of leaf starch concentration on CO, assimilation in soybean. Plant Physiol. 57:560-563.

Plaut, Z., M.L. Mayoral, and L. Reinhold. 1987. Effect of altered sink source ratio on photosynthetic metabolism of source leaves. Plant Physiol. 85:786-791.

Powles, S.B. 1984. Photoinhibition of photosynthesis induced by visible light. Annu. Rev. Plant Physiol. 35:15-44.

Ranney, T. G., N.L. Bassuk, and T.H. Whitlow. 1991. Osmotic adjustment and solute constituents in leaves and roots of water-stressed cherry (Prunus) trees. J. Amer. Soc. Hort. Sci. 116:684-688.

Robinson, S.P. and D.A. Walker. 1981. Photosynthetic carbon reduction cycle, p. 193-236. In: J. Preiss (ed.). The biochemistry of plants. vol. 8. Academic Press, New York.

Roper, T. R., J.D. Keller, W.H. Loescher, and C.R. Rem. 1988. Photosynthesis and carbohydrate partitioning in sweet cherry: Fruiting effects. Physiol. Plant. 72:42-47.

Sage, R.F. and T.D. Sharkey. 1987. The effect of temperature on the occurrence of $\mathrm{O}_{2}$ and $\mathrm{CO}_{2}$ insensitive photosynthesis in field-grown plants. Plant Physiol. 84:658-664.

Sams, C.E. and J.A. Flore. 1982. The influence of age, position, and environmental variables on net photosynthetic rate of sour cherry leaves. J. Amer. Soc. Hort. Sci. 107:339-344.

Sams, C.E. and J.A. Flore. 1983. Net photosynthetic rate of sour cherry (Prunus cerasus L. 'Montmorency') during the growing season with particular reference to fruiting. Photosynth. Res. 4:307-316.

Sasek, T.W., E.V. DeLucia, and B.R. Strain. 1985. Reversibility of photosynthetic inhibition in cotton after long-term exposure to elevated $\mathrm{CO}_{2}$ concentrations. Plant Physiol. 78:619-622.

Satoh, M., P.E. Kriedemann, and B.R. Loveys. 1977. Changes in photosynthetic activity and related processes following decapitation in mulberry trees. Physiol. Plant. 41:203-210.

Sawada, S., Y. Hasegawa, M. Kasai, and M. Sasaki. 1989. Photosynthetic electron transport and carbon metabolism during altered source/sink balance in single-rooted soybean leaves. Plant Cell Physiol. 30:691698.

Schaffer, B., K. Liu, E.E. Goldschmidt, C.D. Boyer, and R. Goren. 1986. Citrus leaf chlorosis induced by sink removal: Starch, nitrogen, and chloroplast ultrastructure. J. Plant Physiol. 124:111-121.

Seemann, J.R., J.A. Berry, S.M. Freas, and M.A. Krump. 1985. Regulation of ribulose bisphosphate carboxylase activity in vivo by a lightmodulated inhibitor of catalysis. Proc. Natl. Acad. Sci. 82:8024-8028.

Sharkey, T.D. 1985. Photosynthesis in intact leaves of $\mathrm{C}_{3}$ plants: Physics, physiology and rate limitations. Bet. Rev. 51:53-105.

Sharkey, T.D. and P.J. Vanderveer. 1989. Stromal phosphate concentration is low during feedback limited photosynthesis. Plant Physiol. 91:679-684.

Steele, R.G.D. and J.H. Torrie. 1980. Analysis of covariance, p. 401437. In: Principles and procedures of statistics. A biometrical approach. McGraw-Hill, New York.

Stitt, M., A. Von Schaewen, and L. Willmitzer. 1990. "Sink" regulation of photosynthetic metabolism in transgenic tobacco plants expressing yeast invertase in their cell wall involves a decrease of the Calvin-cycle enzymes and an increase in glycolytic enzymes. Planta 183:40-50. 
Tschaplinski, T.J. and T.J. Blake. 1989a. Photosynthetic reinvigoration of leaves following shoot decapitation and accelerated growth of coppice shoots. Physiol. Plant. 75: 157-1 65.

Tschaplinski, T.J. and T.J. Blake. 1989b. The role of sink demand in carbon partitioning and photosynthetic reinvigoration following shoot decapitation. Physiol. Plant. 75:166-173.

Usuda, H. and G.E. Edwards. 1982. Influence of varying $\mathrm{CO}_{2}$ and orthophosphate concentrations on rates of photosynthesis, synthesis of glycolate and dihydroxyacetone phosphate by wheat chloroplasts. Plant Physiol. 69:469-473.

Von Caemmerer, S. and G.D. Farquhar. 1984. Effects of partial defoliation, changes of irradiance during growth, short-term water stress and growth at enhanced $\mathrm{p}\left(\mathrm{CO}_{2}\right)$ on the photosynthetic capacity of leaves of Phaseolus vulgaris L. Planta 160:320-329.

Wareing, P.F., M.M. Khalifa, and K.J. Treharne. 1968. Rate-limiting processes in photosynthesis at saturating light intensities. Nature 220453-457.

Warren Wilson, J. 1966. An analysis of plant growth and its control in Arctic environments. Ann. Bet. 30:383-402.

Warren Wilson, J. 1972. Control of crop processes, p. 7-30. In: A.R. ap Rees, K.E. Kockshull, D.W. Hand, and R.G. Hurd (eds.). Crop processes in controlled environments. Academic Press, New York.

Wildman, S.G. 1967. The organization of grana-containing chloroplasts in relation to location of some enzymatic systems concerned with photosynthesis, protein synthesis, and ribonucleic acid synthesis, p. 295-3 19. In: W.T. Goodwin (ed.). Biochemistry of chloroplasts. vol. 2. Academic Press, New York.

Williams, J.H.H. and J.F. Farrar. 1988. Endogenous control of photosynthesis in leaf blades of barley. Plant Physiol. Biochem. 26:503-509.

Woolhouse, H.W. 1967. The nature of senescence in plants. Symp. Soc. Expt. Biol. 21:179-213. 